Key Words: Fuel Relocation PRA

Safety Analysis

Risk Assessment

Severe Accidents

Retention: Lifetime

\title{
MELMRK 2.0: A DESCRIPTION OF COMPUTER MODELS AND RESULTS OF CODE TESTING
}

\author{
by \\ V. Denny and A. Mertol \\ Science Applications International Corporation \\ Edited by \\ R.S. Wittman \\ Westinghouse Savannah River Company
}

Issued: May 31, 1992 


\section{FOREWORD}

The MELMRK computer code was developed to analyze early stages of reactor fuel relocation during the course of a postulated severe accident for the Level 2 Probabilistic Risk Assessment (PRA). Since the data base of fuel assembly melting is limited, initial attemps to characterize fuel melt behavior rely primarily on numerical simulations. The MELMRK computer code solves coupled heat transfer continuum mechanics equations with state-of-the-art computational methods for studying SRS fuel assembly melting. The development of the computational models is documented in the attached report. The model development was performed by SRCT and SAIC to support Level 2 PRA. SAIC staff were the principal analysts and authors of the report. The attached study, therefore, is included as an SAIC report. SRCT staff provided input to, and review of all work performed. Simulations with the code have provided insight regarding inherent time scales for fuel melt as well as the geometric and material property dependence of the problem. While MELMRK was not directly applied to calculate fuel relocation for the Level 2 PRA, MELMRK supplied both phenomenological and theoretical guidance for the development of the MELCOR/SR CSR package. Practically, MELMRK was used to constrain parametric and logic structure of CSR which was used to estimate relocation rates for early stages of fuel melting. The development and application of CSR will be documented in independent WSRC reports on fuel behavior analysis.

Documentation of the Level 2 PRA is scheduled for completion by October 31,1992 , and will consist of the following:

1) A summary report which provides a comprehensive overview of the results of the Level 2 PRA. This report currently exists in draft form as WSRC-91041-DRAFT.

2) A report describing the Accident Progression Event Tree (APET) - the fundamental tool used to perform the Level 2 analysis (issued in March, 1992, as WSRC-RP-91-965). 
3) A series of reports describing the various phenomenological analyses performed to facilitate quantification of the APET (thermal-hydraulics, recriticality, fuel-coolant interactions, etc.).

4) A report summarizing the actual numerical values used to quantify the APET and their justification.

This report falls indirectly into item 3 ) since it documents the formal development of a mechanistic tool used in the quantification of the APET.

An update of the analyses presented is currently under way to support the Rev. 1 Level 2 PRA. These new analyses will consider the restart configuration and power level $(720 \mathrm{MW})$. It is anticipated that the reduced operating power will result in changes to the accident timing and the potential for debris relocation - changes which could have a significant effect in the Level 2 results. 


\section{PROJECT PRA}

\section{DOCUMENT WSRC-RP-92-759}

TTILE MELMRK 2.0: A DESCRIPTION OF COMPUTER MODELS AND RESULTS OF CODE TESTING(U)

\section{Approvals}

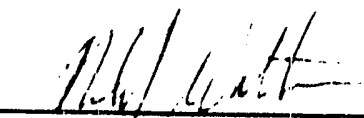

R. S. Wittman, Technical Reviewer

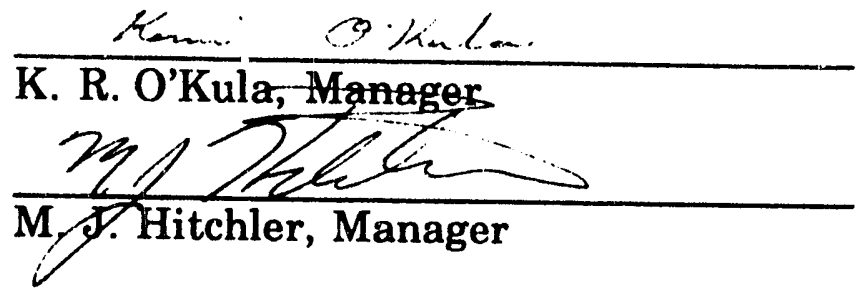

DATE: $5 \ldots$ Y $51 \%$

DATE: $\quad 9-19 \cdot-92$

DATE:

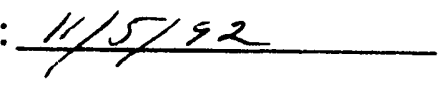




\author{
By \\ V. Denny and A. Mertol \\ Science Applications International Corporation \\ 5150 El Camino Real, Suite C-31 \\ Los Altos, California 94022
}

May 1992 
TABLE OF CONTENTS

$\underline{\text { Page }}$

ABSTRACT $\ldots \ldots \ldots \ldots \ldots \ldots \ldots \ldots \ldots \ldots \ldots \ldots \ldots \ldots \ldots \ldots \ldots$

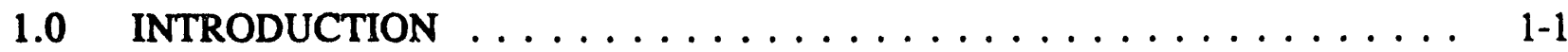

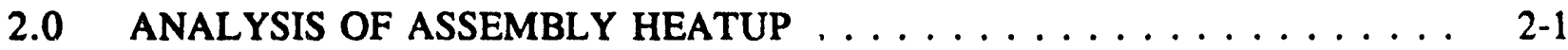

3.0 ANALYSIS OF ASSEMBLY MELTDOWN $\ldots \ldots \ldots \ldots \ldots \ldots \ldots$ 3-1

3.1 Phenomenological Attributes $\ldots \ldots \ldots \ldots \ldots \ldots \ldots \ldots \ldots$ 3-1

3.2 Governing Equations $\ldots \ldots \ldots \ldots \ldots \ldots \ldots \ldots$. . . . . . . .

3.3 Numerical Methods $\ldots \ldots \ldots \ldots \ldots \ldots \ldots \ldots \ldots \ldots$. . . . . . . .

3.3.1 Overview of Nodalization $\ldots \ldots \ldots \ldots \ldots \ldots \ldots$ 3-11

3.3.2 Elimination Algorithm for the In-Depth Thermal Analysis . . . 3-16

3.3.3 Matrix Problem for Advancing Primitive Variables . . . . . 3-20

3.4 Organization of MELMRK 2.0 Relocation Modules . . . . . . . . 3-23

4.0 ILLUSTRATIVE RESULTS $\ldots \ldots \ldots \ldots \ldots \ldots \ldots \ldots \ldots$ 4-1

4.1 Convergence Behavior $\ldots \ldots \ldots \ldots \ldots \ldots \ldots \ldots \ldots$. . . . . .

4.2 Flow Transitions . . . . . . . . . . . . . . . . . . . 4-4

4.3 Mark 31a Meltdown $\ldots \ldots \ldots \ldots \ldots \ldots \ldots \ldots \ldots$. $\ldots \ldots$

5.0 RECOMMENDED FUTURE WORK $\ldots \ldots \ldots \ldots \ldots \ldots \ldots \ldots$ 5-1

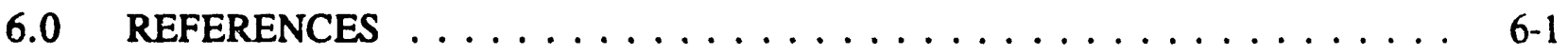

APPENDIX A: INPUT DESCRIPTION $\ldots \ldots \ldots \ldots \ldots \ldots \ldots \ldots \ldots$ A-1 


\section{LIST OF FIGURES}

Page

2-1 Modeling of Single Assembly Heatup/Degradation . . . . . . . . . 2-2

3-1 Schematic of Physical Situation . . . . . . . . . . . . . . 3-2

3-2 Possible Flow Configurations: (a) Rivulet Flow and (b) Film Flow . . . . . 3 3-3

3-3 Illustrative Example of Coexisting Flow Regimes (Rivulet Option) . . . . . . 3-5

3-4 Transitions in Local Flows (Rivulet Option): (a) Transition to Second Control Surface, (b) Transition to Duct Flow, and (c) Complete Solidification . . . . . 3-6

3-5 Interfacial Condition at the Stationary Substrate Surface During

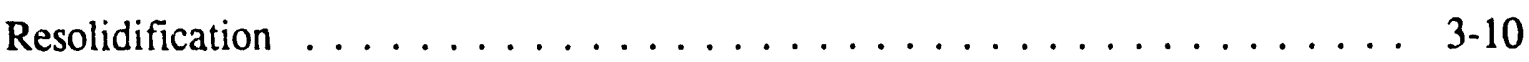

3-6 Leading Edge Nodalization $\ldots \ldots \ldots \ldots \ldots \ldots \ldots \ldots \ldots$ 3-12

3-7 Trailing Edge Nodalization $\ldots \ldots \ldots \ldots \ldots \ldots \ldots \ldots . \ldots \ldots$ 3-14

3-8 Nodalization in Azimuthal Direction $\ldots \ldots \ldots \ldots \ldots \ldots$ 3-15

3-9 Nodalization of Stationary Substrate Layers . . . . . . . . . . . . . 3-18

3-10 Flow Chart for MELMRK 2.0 Early Melt Relocation . . . . . . . . . . . . 3-25

4-1 Code Predictions of Coexisting Flow Regimes for Sample Relocation Problem .......................... 4-5

4-2 Dynamic Flow Transitions Within Dead-Ended Cell . . . . . . . . . . 4 4-6

4-3 Illustration of Vanishingly Thin Flow Stream Resolidification . . . . . . . . 4.8

4-4 Relocation of Mark 31a Assembly Hardware Under Adiabatic Heatup at $\mathrm{t}=500$ Seconds $\ldots \ldots \ldots \ldots \ldots \ldots \ldots \ldots \ldots \ldots \ldots \ldots$. . . . . . . . .

4-5 Relocation of Mark 31a Assembly Hardware Under Adiabatic Heatup at $\mathrm{t}=820$ Seconds $\ldots \ldots \ldots \ldots \ldots \ldots \ldots \ldots \ldots \ldots \ldots \ldots \ldots$. $\ldots \ldots \ldots$

4-6 Fission Product Release During Adiabatic Heatup of Mark 31a Assemblies . . 4-11 


\section{LIST OF TABLES}

Page

4-1 Convergence Behavior of Flow Primitive Variables . . . . . . . . . . . . 4-2

4-2 Convergence Behavior of Stationary Substrate Layer Temperatures and Total Freezing Rate at the Leading Edge Control Volume . . . . . . . . . . . . . 4 4-3

A-1 Variable Definition ........................ A-2

A-2 Input Deck SRPIN.DAT $\ldots \ldots \ldots \ldots \ldots \ldots \ldots \ldots \ldots \ldots$ 


\begin{abstract}
An advanced version of the MELMRK computer code has been developed that provides detailed models for conservation of mass, momentum, and thermal energy within relocating streams of molten metallics during meltdown of Savannah River Site (SRS) reactor assemblies. In addition to a mechanistic treatment of transport phenomena within a relocating stream, MELMRK 2.0 retains the MODI capability for real-time coupling of the in-depth thermal response of participating assembly heat structure and, further, augments this capability with models for selfheating of relocating melt owing to steam oxidation of metallics and fission product decay power.
\end{abstract}

As was the case for MELMRK 1.0, the MOD2 version offers state-of-the-art numerics for solving coupled sets of nonlinear differential equations. Principal features include application of multi-dimensional Newton-Raphson techniques to accelerate convergence behavior and direct matrix inversion to advance primitive variables from one iterate to the next. Additionally, MELMRK 2.0 provides logical event flags for managing the broad range of code options available for treating such features as (i) coexisting tlow regimes, (ii) dynamic transitions between flow regimes, and (iii) linkages between heatup and relocation code modules.

The purpose of this report is to provide a detailed description of the MELMRK 2.0 computer models for melt relocation. Also included are illustrative results for code testing, as well as an integrated calculation for meltdown of a Mark 31a assembly. 


\subsection{INTRODUCTION}

During postulated severe accidents in SRS reactors, fuel and target assemblies undergo heatup transients which lead to melting and relocation of participating materials. Improved understanding of these processes is important to assessments of the consequences of severe accidents in SRS reactors. Of particular import is the extent to which early melt relocation in isolated assemblies can exacerbate accident consequences owing, for example, to thermally induced failure of the universal sleeve housing while moderator liquid is present on the reactor shell-side or to energetic melt-coolant interactions owing to collapse of molten debris into water.

In support of a Level 2 risk assessment for SRS reactor systems [1], a mechanistic computer code (MELMRK) has been developed which provides best-estimate predictions of early melt relocation within fuel/target assemblies. The MODI version of the code was prepared assuming that details of melt flow thermal-hydraulics (which are coupled to the in-depth thermal response of assembly structure) could be replaced by simple engineering approximations. As discussed in Ref. [1], this approach was burdened by an extensive logic structure for effecting control over computational options.

The purpose of this report is to describe the MOD2 version of the MELMRK code, which includes detailed models for thermal-hydraulics processes in relocating melt flows. As was the case for MOD1, the MOD2 version of the code employs state-of-the-art numerics for solving coupled sets of nonlinear differential equations. A noteworthy accomplishment is the replacement of the in-depth heat conduction problem for participating heat structures by complex algebraic equations which depend only on flow variables.

A detailed description of the capabilities of MELMRK 2.0 is presented below. For completeness, the presentation begins with a brief description in Section 2.0 of the heatup analysis for stationary elements of assembly structure. Enhancements to relocation modeling are then described in Section 3.9, followed by results of selected calculations for testing the new meltdown module in Section 4.0. Recommendations for further enhancement and testing of MELMRK capabilities are then presented in Section 5.0. 


\subsection{ANALYSIS OF ASSEMBLY HEATUP}

During inadequate cooling of SRS reactor assemblies, internal heat generation within fuel or target tubes may result, firstly, in voiding of flow channels and, secondly, in differential heatup of assembly hardware. The function of the heatup module in the MELMRK code is to predict principal features of overheating transients, such as liquefaction of materials, steam oxidation of metallics, and release of volatile fission products. For a given assembly tube, the analysis considers transient heat conduction in composite media subject to heat/mass exchange with extemal flow of coolant liquid and/or steam-hydrogen mixture. The physical situation is illustrated in Figure 2-1.

Owing to large magnitudes of radial heat transfer conductances (essentially $k / \Delta r$ ), a lumped capacitance approximation to the thermal response of each distinct sublayer of an assembly tube (including late-stage oxide scales and/or resolidified melt) is a reasonable approximation. (This choice offers a convenient basis, as well, for treating phase changes.) For a given control volume $\left(\Delta V=A_{C} \Delta z^{\prime}\right.$, where $A_{C}$ is cross-sectional area and $z^{\prime}$ is axial distance), the resulting partial difference equation assumes the following form:

$$
\frac{\mathrm{d}}{\mathrm{dt}}(\rho \Delta \mathrm{Vh})=\dot{\mathrm{Q}}_{\mathrm{v}}+\dot{\mathrm{Q}}_{\mathrm{L}, \mathrm{r}}-\dot{\mathrm{Q}}_{\mathrm{c}, \mathrm{r}+\Delta r}+\dot{\mathrm{Q}}_{\mathrm{c}, \mathrm{z}^{\prime}}-\dot{\mathrm{Q}}_{\mathrm{c}, \mathrm{z}^{\prime}+\Delta z^{\prime}}
$$

where, $\rho$ is density, $\hat{h}$ is enthalpy, $\dot{\mathrm{Q}}_{\mathrm{v}}$ is fission product decay power, and $\dot{\mathrm{Q}}_{\mathrm{c}, r} / \dot{\mathrm{Q}}_{\mathrm{c}, z}{ }^{\prime}$ are heat conduction rates in radial and axial directions, respectively.

Application of Eq. (1) to successive layers of a given tube gives a (radially coupled) set of partial difference eouations. These are reduced to algebraic form by writing backward difference approximations to the storage terms, and evaluating the axial heat conduction terms in terms of previous time-stsp values of the axial temperatur is distribution (i.e., explicitly). (Election of an implicit treatment for radial heat conduction is of paramount importance when the thermal state of stationary heat structures is disturbed by relocating melt, since the in-depth 


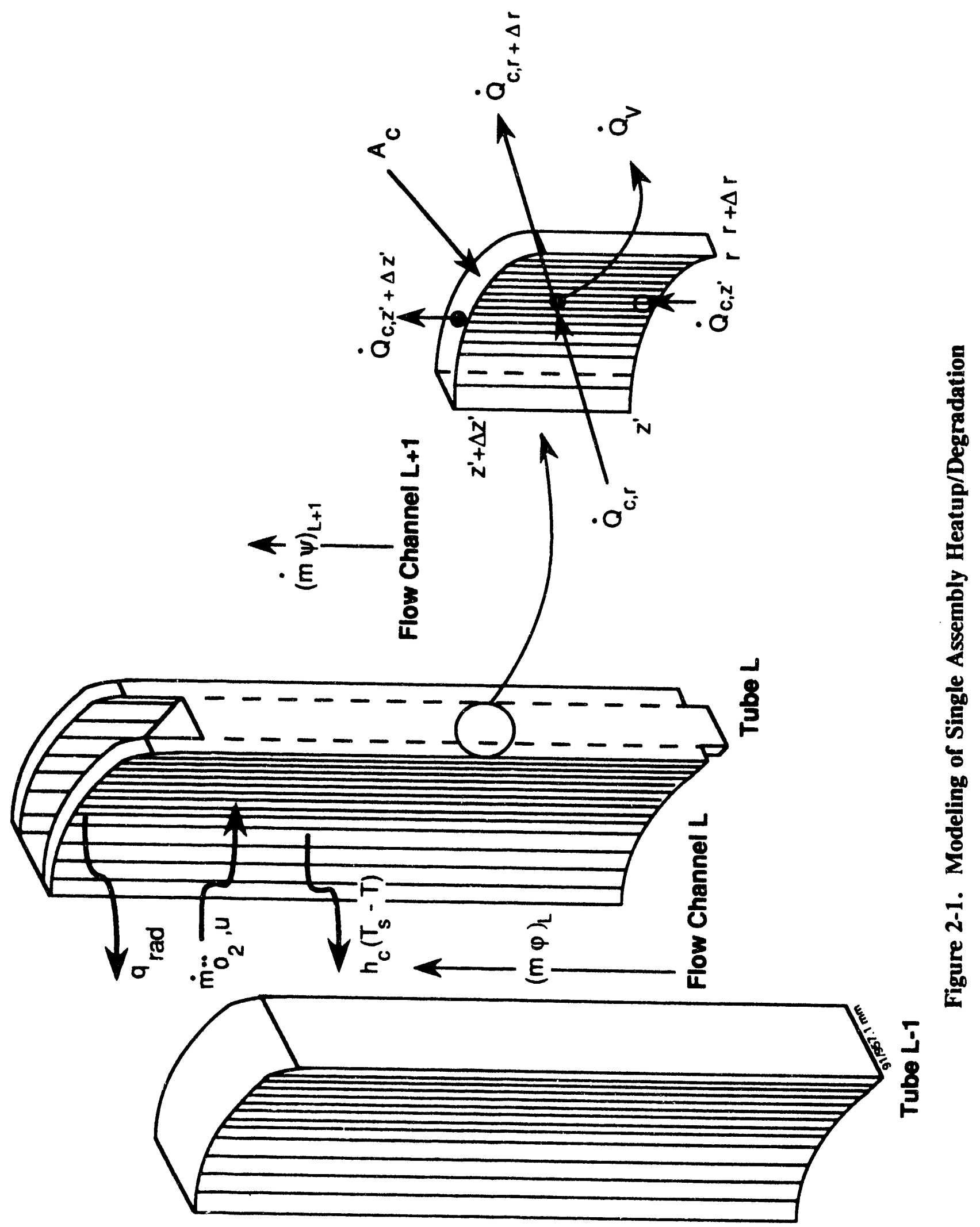


thermal response of successive layers is incompletely developed owing to short residence timesnodalization details under conditions of exposure to relocating melt are discussed in Section 3.3.)

The set of algebraic equations for the implicit radial heat conduction problem is coupled further to coolant channel thermal-hydraulics via interfacial boundary conditions,

$$
\dot{\mathrm{Q}}_{c, \mathrm{r}_{\mathrm{s}}}=\mathrm{h}_{\mathrm{c}} \mathrm{A}_{\mathrm{s}}\left(\mathrm{T}_{s}-\mathrm{T}\right)+\dot{\mathrm{Q}}_{\mathrm{rx}}
$$

where, $h_{c}$ is the convective heat transfer coefficient, $A_{s}$ is interfacial area, and $T_{s} / T$ are temperatures at the surface and in the free stream, respectively. Under conditions of surface oxidation,

$$
\dot{\mathrm{Q}}_{\mathrm{rx}}=\mathrm{A}, \dot{\mathrm{m}}_{\mathrm{o}_{2}, \mathrm{u}}^{\prime \prime} \hat{\mathrm{Q}}_{\mathrm{ox}}
$$

where, $\dot{\mathrm{m}}_{\mathrm{o}, \mathrm{u}}$ is the oxygen flux across the (growing) oxide layer (a result of kinetics experiments) and $\hat{Q}_{o x}$ is the specific heat of reaction.

Two options are available for coupling MELMRK tc channel flow behavior. In the first, a stand-alone version can be exercised using simple one-dimensional models for representing conserved properties:

$$
\frac{d}{d t}\left(\rho V_{r} \phi\right)=(\dot{m} \phi)_{Z^{\prime}}-(\dot{m} \phi)_{z^{\prime}+\Delta Z^{\prime}}+S_{\phi}
$$

In Eq. (4), $\phi=1, \mathrm{~m}_{1}$ (mass-fraction steam), and $\hat{\mathrm{h}}$ (mixture enthalpy), respectively, for conservation of mass, mass-species and thermal energy within a given control volume $\left(V_{f}=A_{f} \Delta z^{\prime}\right)$. Assuming further that the axial pressure distribution is uniform for a time interval $\Delta t$, the axial distribution of mass flow rates is given by: 


$$
\dot{m}_{z^{\prime}+\Delta z^{\prime}}=\dot{m}_{z^{\prime}}-V_{f} \partial \rho / \partial t
$$

where, $\dot{\mathrm{m}}_{\mathbf{z}} \cdot$ at the water/gas interface is extracted from a heat balance on immersed heat structures [1].

In the second option, (time-dependent) values of flow temperature distributions and convective heat transfer coefficients are presumed to be available. In addition, axial distributions of mass flow rate, mixture density, and steam mass fraction are required when steam oxidation of metallics takes place.

The heatup analysis for a given axial node within each assembly tube is continued until all available mass has been depleted by relocation to (lower) levels. Details of current capabilities for treating relocation processes in SRS reactor assemblies are given in the following section. 


\subsection{ANALYSIS OF ASSEMBLY MELTDOWN}

\subsection{Phenomenological Attributes}

In addition to (MOD1) capabilities for predicting the in-depth thermal response of stationary heat structures, the MOD2 version of the MELMRK code includes a detailed treatment of heat, mass, and momentum transport within a relocating flow "packet." Key features of the MOD2 approach are: (i) physically based options for initialization of flow-packet geometries, (ii) accommodation of coexisting flow regimes, (iii) time-dependent transitions between flow regimes, and (iv) fully implicit treatment of thermal and hydraulic interactions between the flow packet and adjacent media (coolant water, steam-hydrogen mixture, and assembly structure). Secondarily, the analysis methodology incorporates self-heating of relocating melt owing to oxidation of metallics and fission product decay power.

Equally important, the methodological approach is complimented by encoded logic that automates flow regime transitions, selects probable pathways for migration of the flow packet, sets initial conditions for involvement of structural mass subsumed by the flow-packet leading edge, and provides linkage between heatup and melt relocation modules. Further details of the overall analysis approach are discussed in the following paragraphs: principal attributes of the physical situation are depicted in Figure 3-1.

The initial geometry of ejected melt is controlled by user inputs. At present, these consist of the azimuthal extent of the flow packet as well as its thickness in the radial direction. For Mark $16 \mathrm{~b}$ assemblies, a possible configuration is a rivulet of molten fuel which may bridge the gap between adjacent cylinders. For Mark $31 \mathrm{a}$ assemblies, on the other hand, election of a contiguous film in contact with the "parent" cylinder is, perhaps, a reasonable choice. These choices are illustrated in Figure 3-2.

Given user-specified initial conditions, including axial velocity, the contiguous flow packet is presumed to relocate under the influence of gravity and drag forces along (possibly degraded) flow channels of the assembly. This may result in coexisting flow regimes; typical code options 


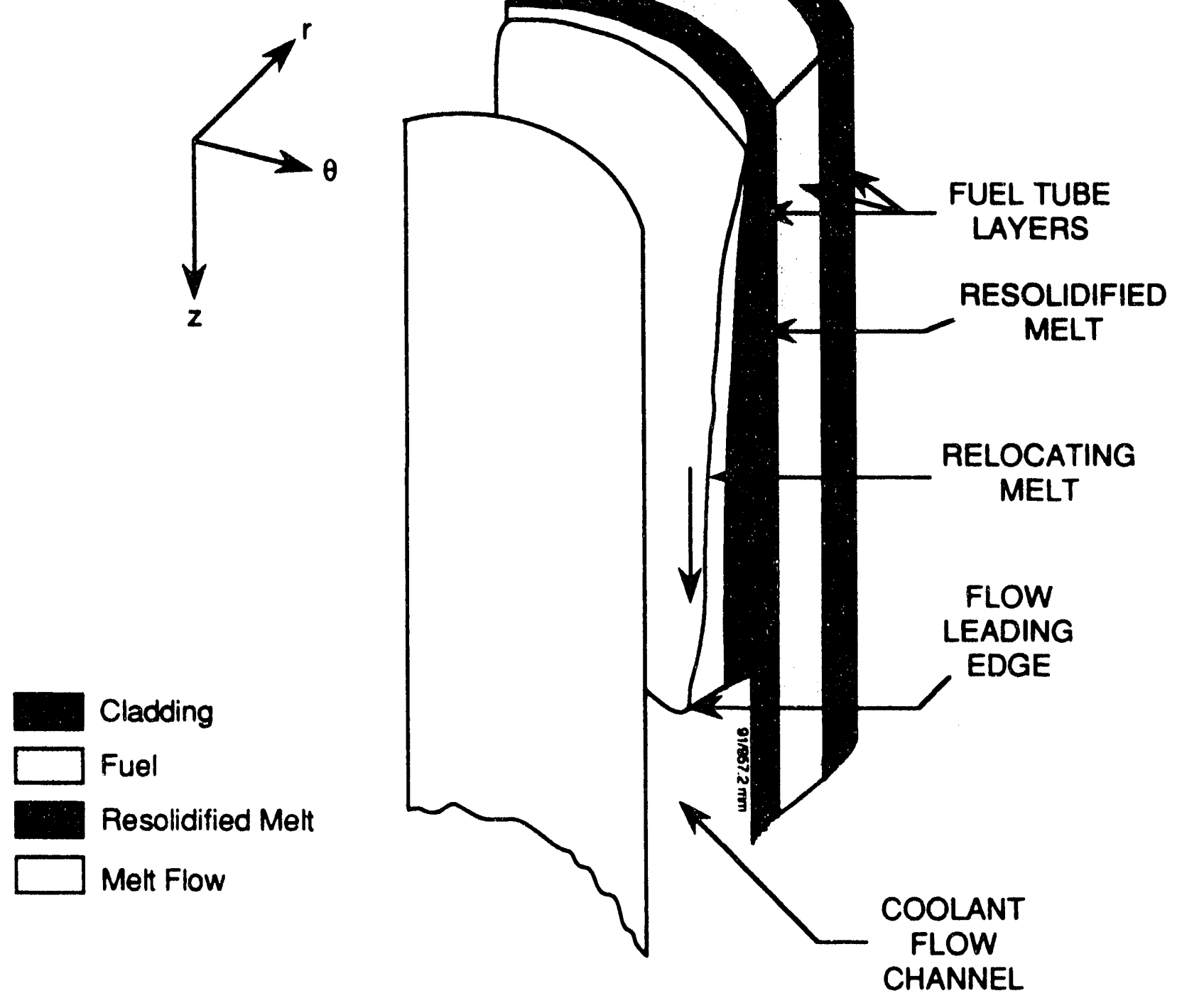

Figure 3-1. Schematic of Physical Situation 

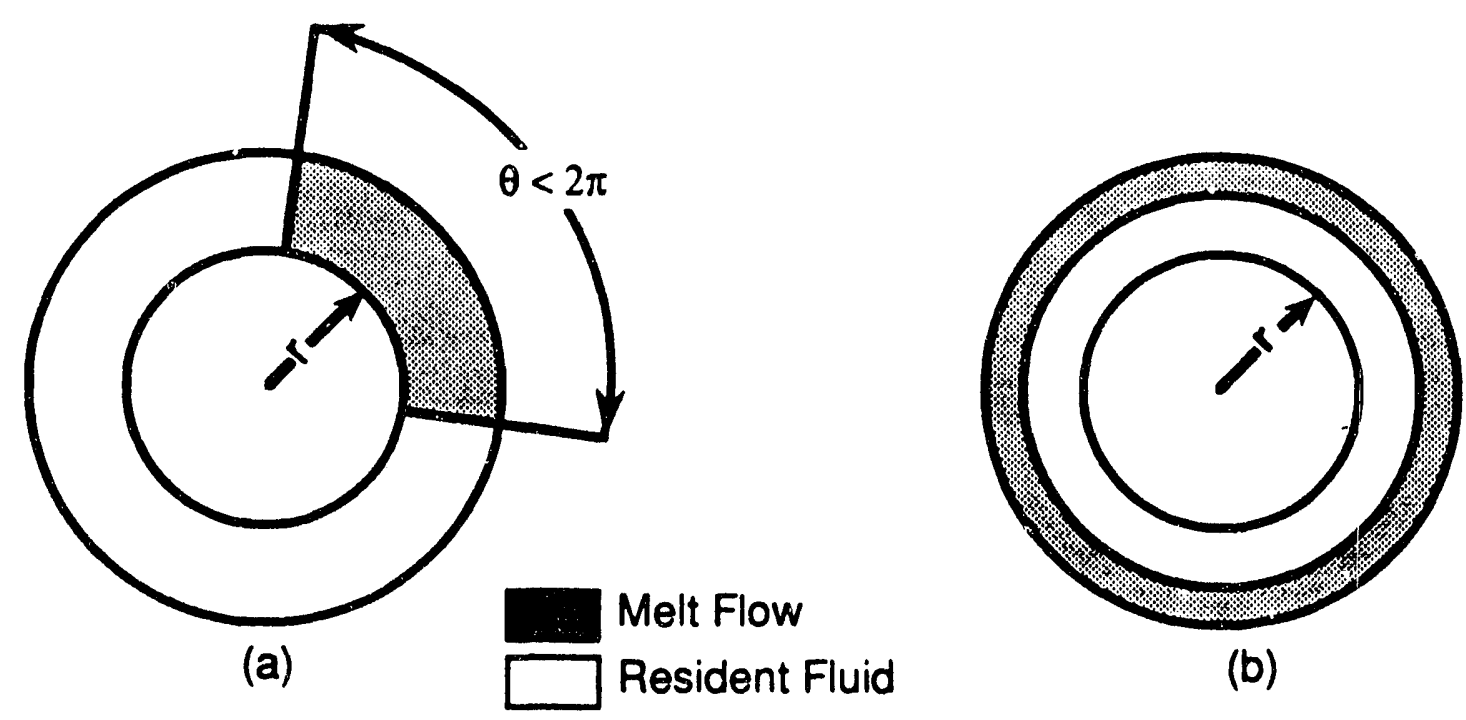

(b)

Figure 3-2. Possible Flow Configurations: (a) Rivulet Flow and (b) Film Flow 
for simulating rivulet-like behavior are illustrated in Figure 3-3. (Similar options have been developed for cases in which the initial configuration of the flow packet is a contiguous film, recall Figure 3-2.) In Section A-A of the figure, a rivulet in contact with the outer control surface is seen to enter a narrow gap (Section B-B), resulting in interactions with two control surfaces. Below Section B-B, the flow packet passes through a major reduction in channel flow area (Section C-C), wherein local flow behavior is subject to gradients in pressure. On emerging from this reduced area section, the flow may next revert to a free surface configuration; depicted in Section D-D is a freely falling jet. These and other permutations of coexisting flow regimes are currently operational in MELMRK 2.0 including, for example, transverse flow from one channel to another or transverse spreading of the leading edge region upon encountering a flow blockage (see Section 4.2).

In addition to experiencing coexisting flow regimes, the flow-packet may also experience transitions between flow regimes at fixed locations along the flow path. Current MELMRK capabilities are illustrated in Figure 3-4, again, for rivulet-like flow. In Figure 3-4, a local segment of the rivulet grows radially inward, intersecting a second control surface. (For the innermost channel, growth is terminated if $r_{i} \leq 0$.) In Figure 3-4, an azimuthally growing rivulet undergoes transition to duct flow, i.e., $\theta=\theta_{\max }$. (In MELMRK, prior deposits of resolidified melt can be azimuthally segregated to simulate resolidification of a rivulet.) Finally, formation of a fully blocked flow channel may occur, as depicted in Figure 3-4. When such transitions occur, logical "flags" automate inclusion (or deletion) of the additional relocation physics (e.g., addition of a second heat structure, constraint of azimuthal growth, formation of a full blockage, etc.).

In concert with detailed models for flow phenomena, the MOD2 version of MELMRK retains previous features of thermal and hydraulic interactions between the flowing melt and resident media. For example, when the temperature of resident media differs from that of relocating melt, the overall thermal-hydraulics problem, which inherently is nonlinear, may also be strongly coupled. This is particularly evident when resolidification occurs within a flow passage of reduced area (recall Sections A-A through C-C in Figure 3-3). In the new version of MELMRK, the overall relocation analysis is solved implicitly, utilizing quasi-linearization, 
Relocating Flow Packet

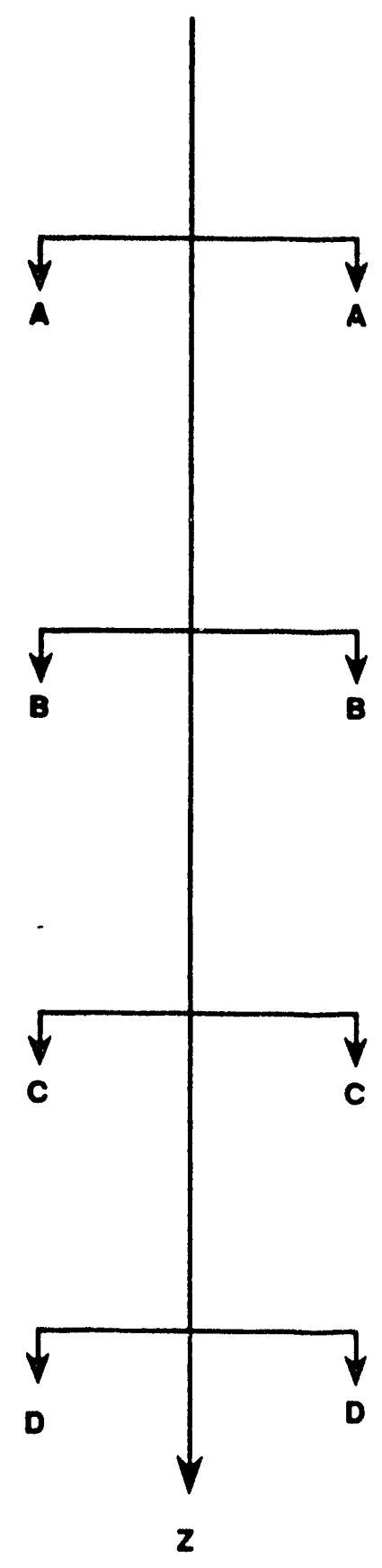

\section{Section Views}

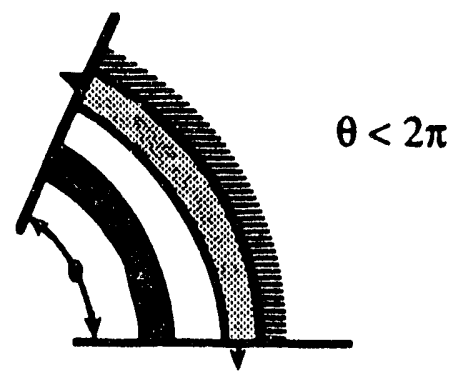

B-B

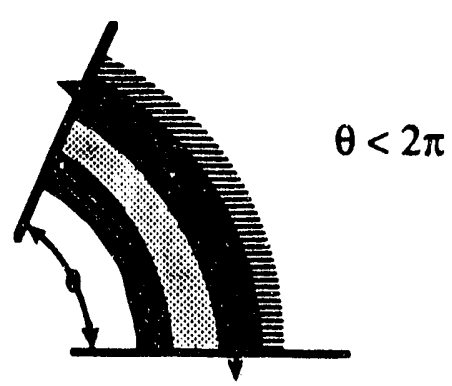

C.C

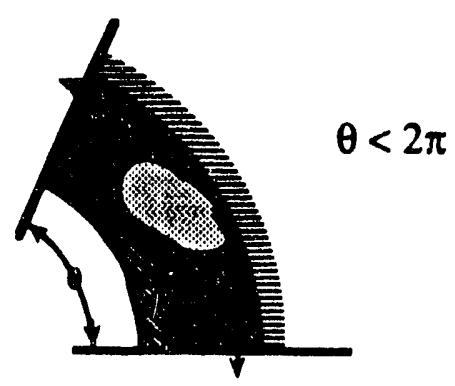

D-D

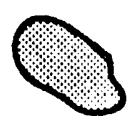

Figure 3-3. Illustrative Example of Coexisting Flow Regimes (Rivulet Option) 

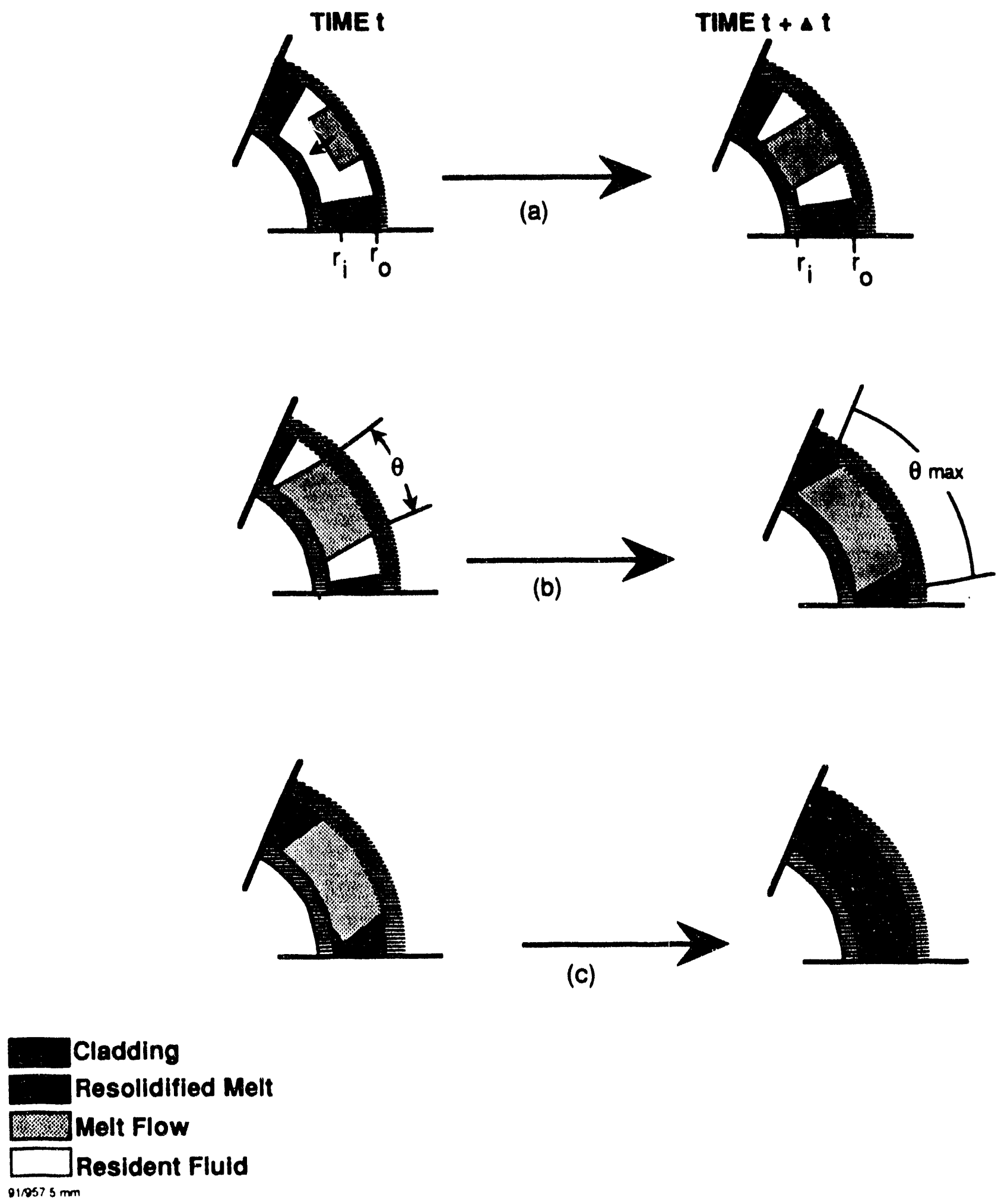

Figure 3-4. Transitions in Local Flows (Rivulet Option): (a) Transition to Second Control Surface, (b) Transition to Duct Flow, and (c) Complete Solidification 
successive substitution, and direct matrix inversion to advance primitive variables from one iterate to the next (see Section 3.3).

Although MELMRK 2.0 contains a broad selection of code options for simulating principal features of relocation behavior, capability has yet to be developed for treating even more complex phenomena, such as local branching into (or rejoining of) parallel streams or for segmenting an initially contiguous packet into separate flow elements. Additionally, the new relocation modeling has not been tested for upwards motion when drag forces (owing, say, to high velocity steam) exceed gravity.

\subsection{Governing Equations}

Assuming that thermal-hydraulic interactions between the melt flow and resident media can be treated by means of transfer coefficients and, further, that axial diffusion is negligibly small as compared to advection, the governing conservation equations are hyperbolic. For conservation of mass:

$$
\frac{\partial}{\partial t}(\rho A)+\frac{\partial}{\partial z}\left(\rho A v_{z}\right)=-\dot{m}^{\prime}
$$

where, $\rho$ is mass density, $A$ is flow area, $v_{z}$ is axial velocity, and $m_{s}^{\prime}>0$ is the total rate of freezing per unit axial length of (stationary) heat structure. Owing to effects discussed in Section 3.1 above, both velocity and flow area can vary with position and time.

For momentum, the governing equation assumes the form:

$$
\frac{\partial}{\partial t}\left(\rho A v_{z}\right)+\frac{\partial}{\partial z}\left(\rho A v_{z}^{2}\right)=-\dot{m}_{a}^{\prime} v_{z}-A \frac{\partial P}{\partial z}+\rho A\left(g-\dot{S}_{d} v_{z}\right)
$$

where, $\partial \mathrm{P} / \partial \mathrm{z}$ is the axial pressure gradient, $\mathrm{g}$ is gravitational acceleration, and $\dot{F}_{\mathrm{d}}$ is the total drag coefficient. (For upwards flow, both $g$ and $\dot{\zeta}_{\mathrm{d}}$ would, of course, change sign.) 
Finally, for conservation of energy:

$$
\left.\frac{\partial}{\partial t}(\rho A \hat{h})+\frac{\partial}{\partial z}\left(\rho A v_{z} \hat{h}\right)=-\dot{m}_{3}^{\prime} \hat{h}_{s}\right)+\dot{Q}_{d k}^{\prime}+\dot{Q}_{r x}^{\prime}+\dot{Q}_{1}^{\prime}
$$

where, $\hat{h}$ is enthalpy, subscript $s$ denotes the thermal state at the interface between the flow and adjacent heat structure, and

$$
\begin{aligned}
& \dot{\mathrm{Q}}_{\mathrm{dk}}^{\prime}=\sum_{n=1}^{N} \mathrm{~m}_{\mathrm{n}} \mathrm{W}_{\mathrm{f}}^{\prime} \dot{\mathrm{Q}}_{\mathrm{n}} \\
& \dot{\mathrm{Q}}_{\mathrm{rx}}^{\prime}=P_{\mathrm{rx}} \dot{\mathrm{m}}_{\mathrm{rx}}^{\prime \prime}(\Delta \mathrm{H})_{\mathrm{rx}} \\
& \dot{\mathrm{Q}}_{\mathbf{1}}^{\prime}=-\dot{\mathrm{Q}}_{\mathrm{s}, \mathrm{i}}^{\prime}-\dot{\mathrm{Q}}_{\mathbf{s}, \mathrm{o}}^{\prime}
\end{aligned}
$$

In Eq. (9a), $m_{n}$ is the mass fraction of each fission product species, $W_{f}^{\prime}$ is the total weight of flow per unit length of control volume, and $\dot{Q}_{n}$ is the fission product self-heating for each species. In Eq. (9b), $p_{r x}$ is the perimeter for oxidation of metallics, $\dot{m}_{r x}^{\prime \prime}$ is the rate of oxidation of metallics per unit surface area, and $(\Delta \mathrm{H})_{\mathrm{rx}}$ is the heat of reaction. Finally, in Eq. (9c):

$$
\dot{\mathrm{Q}}_{\mathrm{s}, \mathrm{i} / \mathrm{o}}^{\prime}=\mathrm{h}_{\mathrm{i} / \mathrm{o}} \rho_{\mathrm{i} / \mathrm{o}} \frac{\theta}{2 \pi}\left(\mathrm{T}_{\mathrm{f}}-\mathrm{T}_{\mathrm{s}, \mathrm{i} / \mathrm{o}}\right)=\xi_{\mathrm{i} / \mathrm{o}} \theta\left(\mathrm{T}_{\mathrm{f}}-\mathrm{T}_{\mathrm{s}, \mathrm{i} / \mathrm{o}}\right)
$$

where, $h_{i / o}$ are convective heat transfer coefficients at inner/outer surfaces of adjacent heat structures, $\rho_{\mathrm{i} / \mathrm{o}}$ are associated wetted perimeters, $\theta$ is the azimuthal extent of the flow packet, $T_{\mathrm{f}}$ is flow temperature, and $T_{s, i / o}$ are surface temperatures.

In the absence of mass exchange, the interfacial temperatures $T_{, j / \mathrm{o}}$ are a part of the (implicit) analysis for the in-depth heat conduction problem (see Section 3.3). In the presence of mass 
exchange, these temperatures are equal to $T_{10}$, the freezing temperature. In exchange for this simplification, the freezing rate depends on the in-depth heat conduction problem via:

$$
\dot{m}_{s}^{\prime}=\left(\dot{Q}_{u, 0}^{\prime}-\dot{Q}_{\mathbf{s}, 0}^{\prime}\right) / \hat{h}_{e f r}
$$

where, $\dot{Q}_{u, o}$ and $\dot{Q}_{\mathbf{s}, 0}$ are illustrated in Figure 3-5 and $\hat{h}_{\mathrm{eff}}=\mathrm{m}_{1} \hat{\mathrm{h}}_{\mathrm{l}}$ is the effective heat of fusion for resolidification of a slurry with mass fraction liquid equals to $m_{1}$. (Since the thermal resistance of resolidifying layer, which initially has zero thickness, is small as compared to that of in-depth layers, analysis of freezing rates is strongly coupled to the in-depth heat conduction problem.)

In addition to a complex interfacial condition for the in-depth problem, analysis of melt relocation requires specification of boundary conditions for the (first order) hyperbolic equations. For continuity and momentum, approach taken is to specify zero gradients for either flow area or velocity at leading/trailing edge positions. For the pressure field, it is assumed that ambient pressure applies at the leading/trailing edges of the flow packet. For the case of inertial flow into a dead-ended gas volume:

$$
\frac{d}{d t}\left(\frac{P_{L} M_{e}}{R T_{e}} V_{c}\right)=\frac{d}{d t}\left(P_{L} V_{e}\right)=0
$$

where, $P_{L}$ is pressure at the leading edge control volume and $V_{c}$ is flow volume within a deadend cell. 
Zla Cladding

$\square$ Fuel

Resolidified Melt

$\square$ Melt Flow
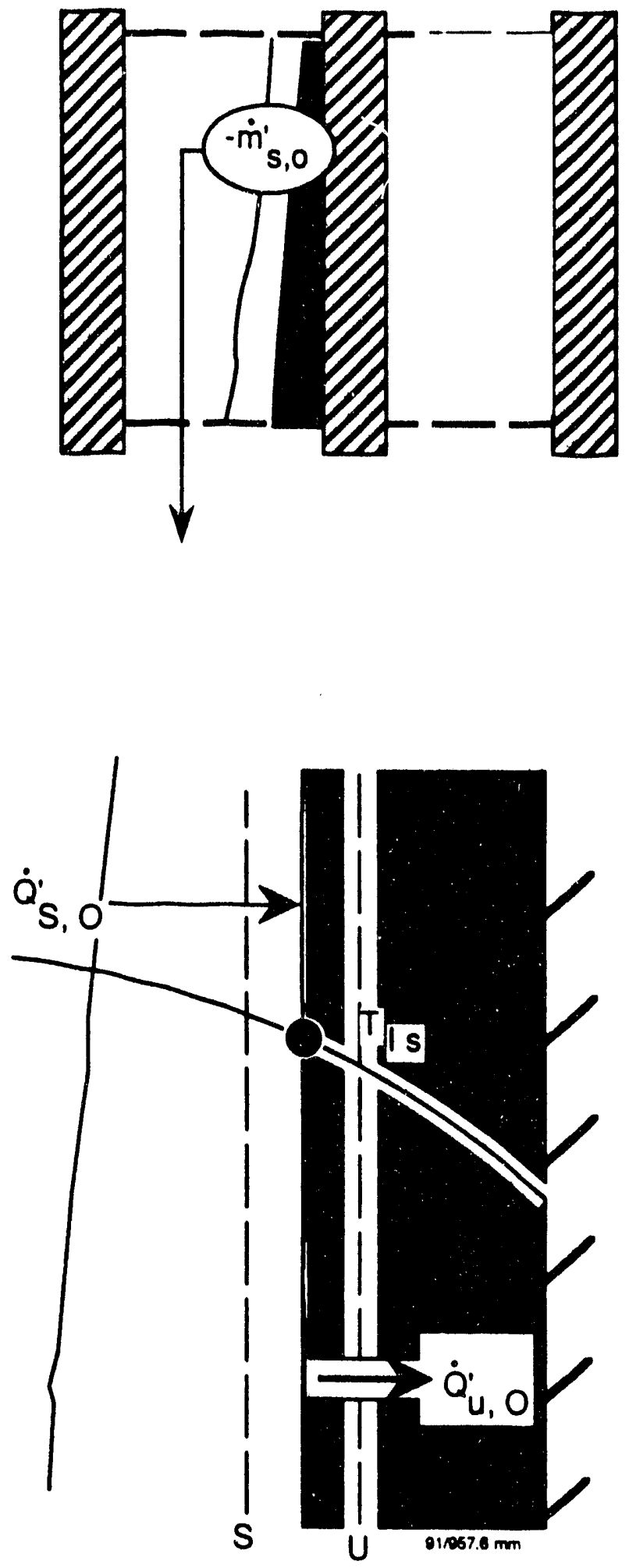

Figure 3-5. Interfacial Condition at the Stationary Substrate Surface During Resolidification 


\subsection{Numerical Methods}

The governing equations for modeling melt relocation processes are solved numerically, using lumped capacitance techniques to reduce sets of differential equations to algebraic form. The resulting sets of algebraic equations are non-linear owing, primarily, to time-varying geometry, which is highly dependent on the velocity field as well as on interfacial inass transfer rates. In addition, the algebraic problem is highly coupled, i.e., involves many dependent variables per equation.

The basic approach for solving coupled non-linear set of algebraic equations is multi-dimensional Newton-Raphson iteration (i.e., quasi-linearization). The iterative process is supported by procedures for eliminating interim variables (geometric variables and in-depin temperature distributions) in favor of primitive variables (axial distributions of flow area, velocity, enthalpy, and pressure). This results in a (sparse) coefficient matrix for relating interactions between primitive variables along the flow-packet path. Direct matrix inversion is then applied to extract improved values of the primitive variables, followed by updates to interim variables.

Further details of the numerical methodology are given in the following sub-sections. Illustrative results for testing the capabilities of MELMRK 2.0 relocation algorithms are then presented in Section 4.0.

\subsubsection{Overview of Nodalization}

As indicated in Section 2.0, a control volume approach is being utilized to analyze heatup of assembly structure. For convenience in relating the effects of melt relocation on assembly heatup and degradation, the relocation analysis is referenced to the (fixed) nodalization grid, which supports the heatup analysis. This is illustrated in Figure 3-6, where the (discrete) flow packet is presumed to interact with sub-sets of the heatup grid. Shown in the figure is a snapshot of the supposed interaction for a case in which the flow packet spans three axial control volumes. Within leading-edge control volumes ( $\mathrm{I}=\mathrm{IMX}, \mathrm{KF}<\mathrm{K} \leq \mathrm{KMX})$, increases in $\delta_{\mathrm{IMX}}$ (owing to inflow from above) result in "entrainment" of mass, mass species, and thermal energy 


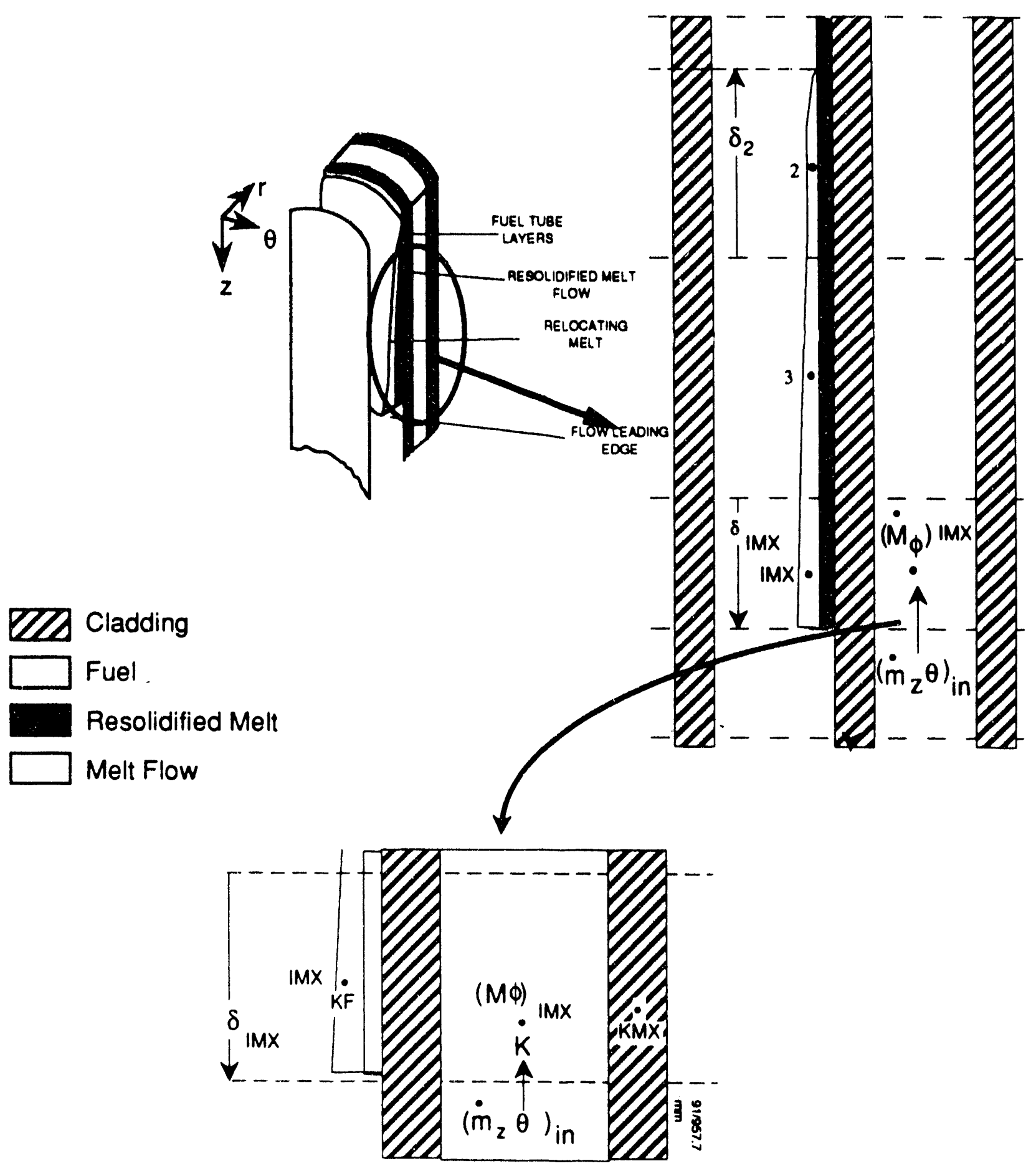

Figure 3-6. Leading Edge Nodalization 
from (undisturbed) conurol volumes in advance of the flow (IMX $+1, K F+1 \leq K \leq K M X)$, where:

$$
\dot{\mathrm{m}}_{\mathrm{z}, \mathrm{in}}=\left(\rho_{\mathrm{K}} \mathrm{A}_{\mathrm{K}} \frac{\mathrm{d} \delta}{\mathrm{dt}}\right)_{\mathrm{IMX}}=\left(\rho_{\mathrm{K}} \mathrm{A}_{\mathrm{K}}^{\prime} \theta \frac{\delta-\delta^{\bullet}}{\Delta \mathrm{t}}\right)_{\mathrm{IMX}}
$$

Since

$$
A_{K}^{\prime}=0.5\left(r_{K}^{2}-r_{K-1}^{2}\right)
$$

is a constant, $\dot{\mathrm{m}}_{\mathrm{z}, \text { in }}$ is seen to be a function of $\delta_{\mathrm{IMX}}$ and $\theta_{\mathrm{IMX}}$. (These inflows contribute to storage of cunservet property, $\mathrm{M} \varphi$, within the growing leading edge nodes.)

For trailing edge control volumes $\left(I=2\right.$ ), diminution of $\delta_{2}$ (owing to outflow of fluid into node 3) produces similar entrainment effects (see Figure 3-7), now for nodes that are "retired" to the heatup code $(I=1, K F+1 \leq K \leq K M X)$. (When $\delta_{2} \leq 0$, the resultant "cupmixed" state of these nodes replaces that which previiled prior to passage of the flow packet.)

Actually, the general nodalization approach in MELMRK is more elaborate than the impression given in Figures 3-6 and 3-7. In addition to racial/axial nodes for interaction with an outer tube $(\mathrm{KF} \leq \mathrm{K} \leq \mathrm{KMX})$, nodes may be present for the inner tube (KMN $\leq \mathrm{K} \leq \mathrm{KF}$ ) or for both inner/outer tubes ( $K M N \leq K \leq K M X)$. And, this nodalization may be dynamic, i.e., may result from radial motion of a free surface into contact with one or the other of the adjacent heat structures (recall Figure 3-4). Furthermore, nodalization may consist of azimuthal degrees of freedom. This is iïustrated in Figure 3-8, where a rivulet bridging the gap between successive tubes is unconstrained in the $\theta$ - direction. Thus, MELMRK nodalization permits peripheral interactions between the principal node $(I, 1, K)$, which is faces on the flow, and a secondary node $(I, 2, K)$ which interacts only with the principal node. Showr in Figure 3-8 is the situation wherein $\theta$ is growitig, the geometric constraint on the flow/debris cross section is taken as: 


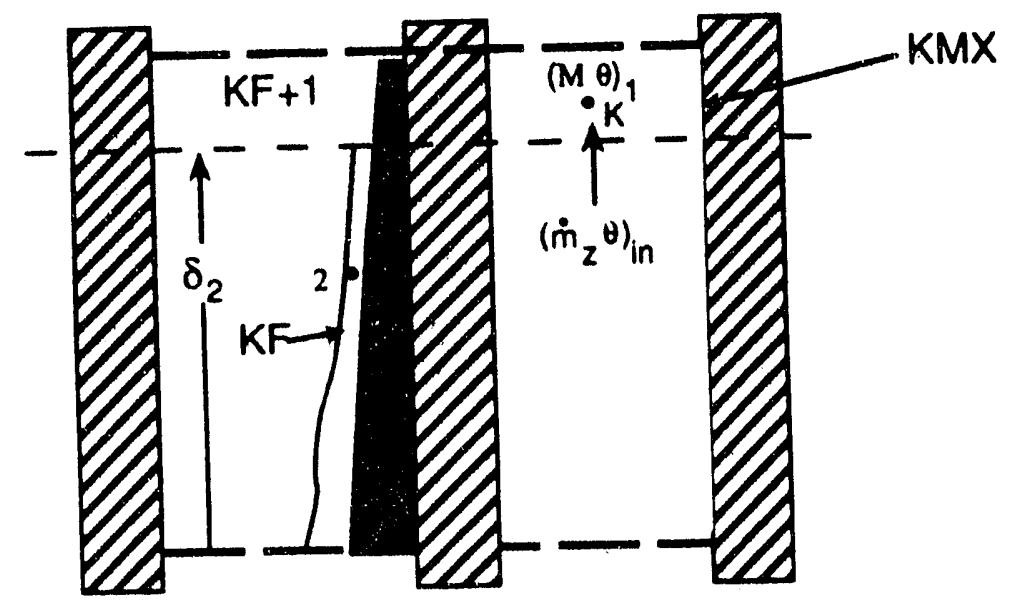

QD Cladding

$\square$ Fuel

Resolidified Melt
$\square$ Melt Flow
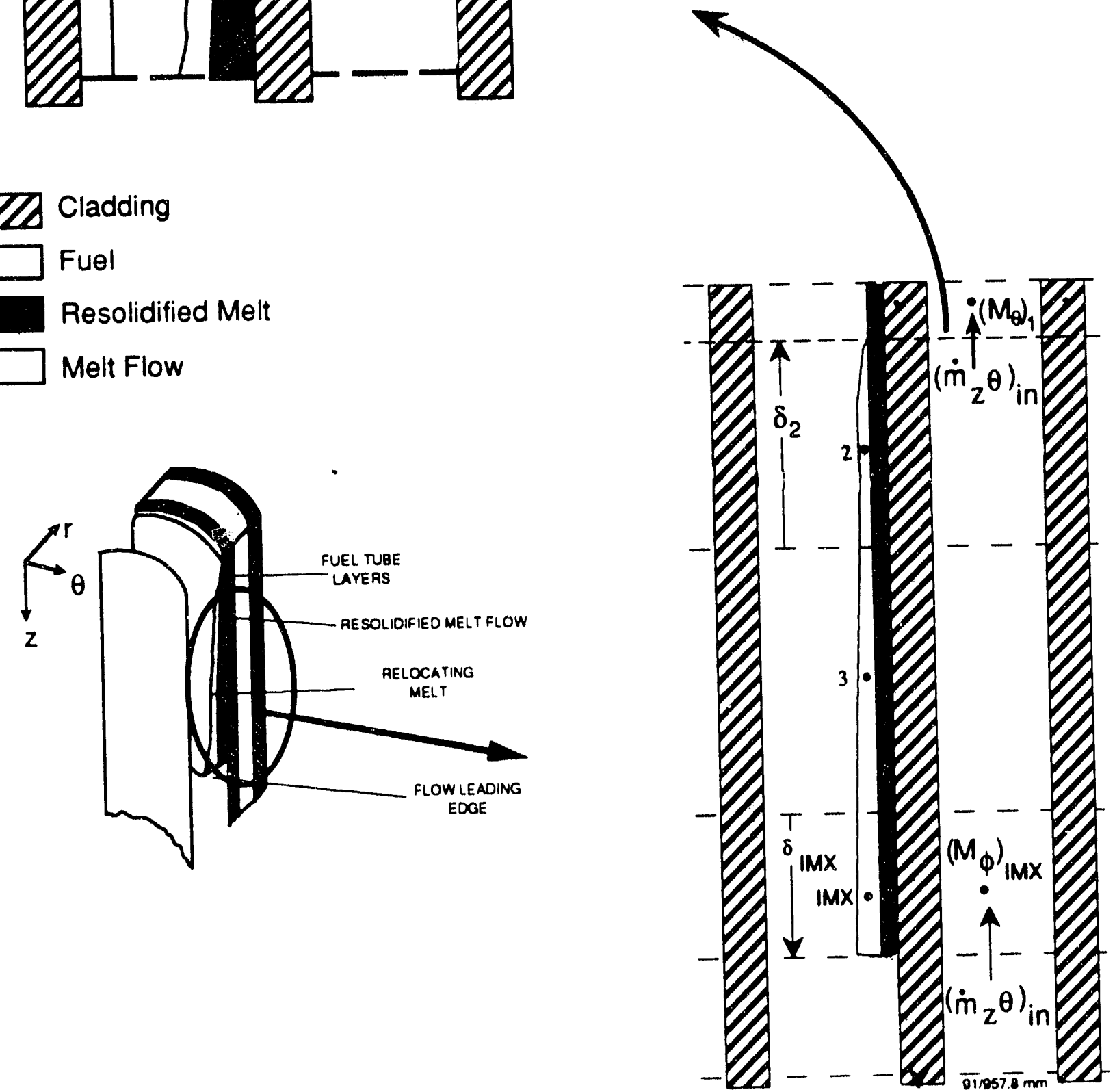

Figure 3-7. Trailing Edge Nodalization 

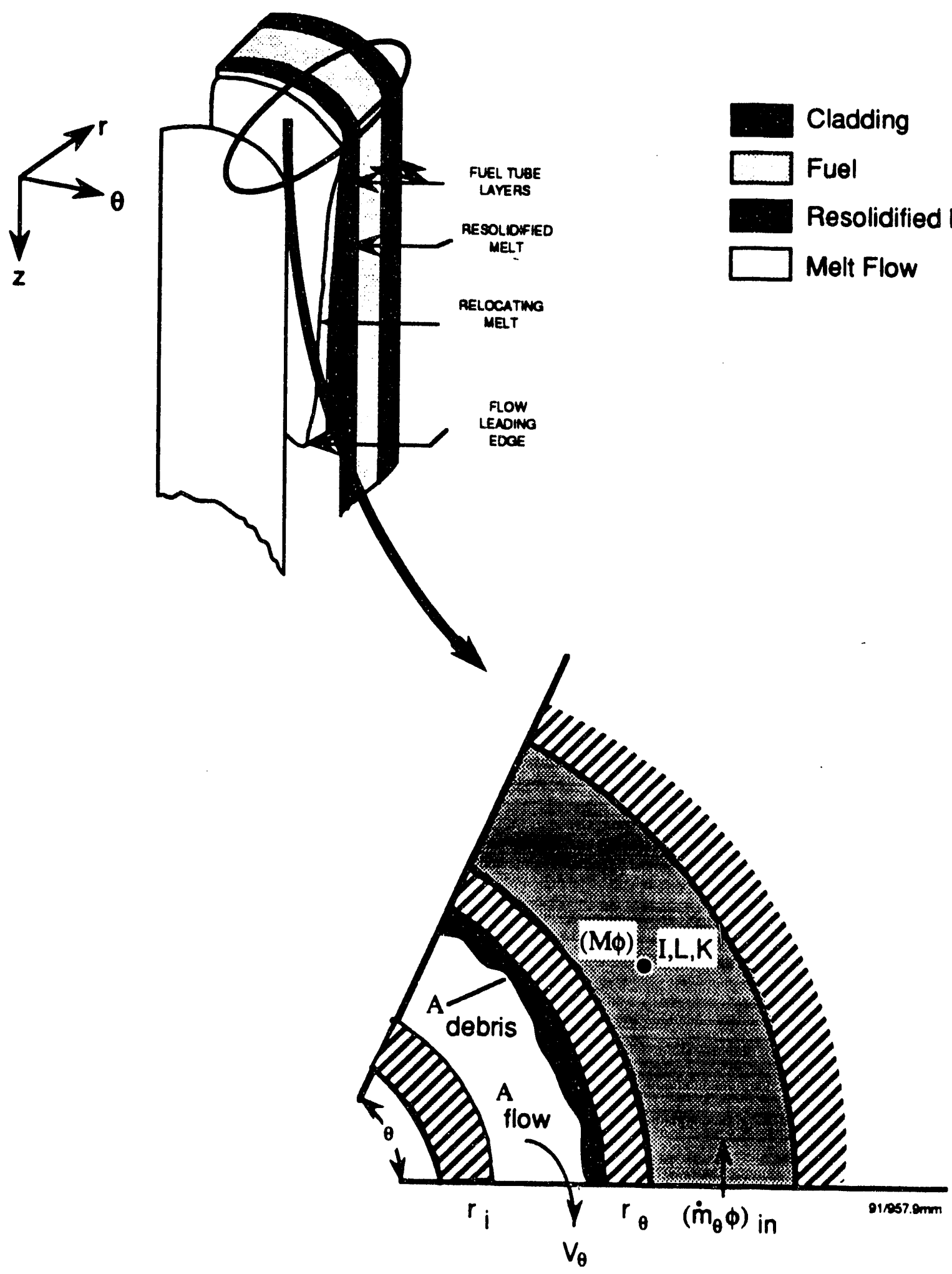

Figure 3-8. Nodalization in Azimuthal Direction 


$$
\pi\left(r_{0}^{2}-r_{i}^{2}\right) \frac{\theta}{2 \pi}=A_{f}^{\prime} \theta=A_{\text {now }}+A_{\text {debris }}
$$

where, $A_{f}$ is a constant

$$
\dot{\rho} \delta \mathrm{A}_{\text {debris }}=\mathrm{W}_{\text {debris }}^{\bullet}+\dot{\mathrm{m}}_{\mathrm{s}}^{\prime} \delta \Delta \mathrm{t}
$$

and $\mathrm{W}_{\mathrm{debris}}^{*}$ is the total mass of resolidified melt at time $\mathrm{t}-\Delta \mathrm{t}$. The associated entrainment rate for the $\mathrm{K}^{\mathrm{th}}$ layer is given by:

$$
\dot{\mathrm{m}}_{\theta, \mathrm{K}}=\rho_{\mathrm{K}} \delta\left(\mathrm{r}_{\mathrm{K}}-\mathrm{r}_{\mathrm{K}-1}\right) \overline{\mathrm{r}}_{\mathrm{K}}\left(\frac{\theta-\theta^{\bullet}}{\Delta \mathrm{t}}\right)
$$

a function of node height $\delta$ (a function, possibly, of the primitive variable $v_{z}$ ) and (the current value of) $\theta$.

\subsubsection{Elimination Algorithm for the In-Depth Thermal Analysis}

As discussed above, the overall approach for advancing the relocation analysis from time $\mathrm{t}-\Delta \mathrm{t}$ to time $t$ involves replacement of the in-depth thermal analysis with complex interfacial boundary conditions which depend only on axial distributions for velocity $\left(v_{v}\right)$, flow area $\left(A_{f}\right)$, and enthalpy $\left(\hat{h}_{f}\right)$, i.e., on the primitive variables. Basically, the approach employs successive substitution, together with multidimensional Newton-Raphson techniques to effect quasilinearized forms of the boundary conditions. These conditions are then incorporated in the partial difference equations for conservation of mass, momentum, and thermal energy to establish the coefficient matrix for the flow control volume analysis. In the development which follows, the numerical methodology is illustrated for flow interactions with the inner surface of the adjacent assembly structure. 
Control Volume Results $(K>K F)$

For a given $\mathrm{K}$,

$$
\frac{(M \hat{h})}{\Delta t_{K}}=\frac{(M \hat{h})^{\bullet}}{\Delta t_{k}}+\dot{Q}_{c, K-1}-\dot{Q}_{c, K}+\sum(\dot{m} \hat{h})_{\text {im }}-\sum(\dot{m} \hat{h})_{\text {out }}
$$

where, for example,

$$
\dot{\mathrm{Q}}_{\mathrm{c}, \mathrm{K}-1}=\frac{\delta \theta\left(\mathrm{T}_{\mathrm{K}-1}-\mathrm{T}_{\mathrm{K}}\right)}{\left[\frac{\delta \mathrm{r}}{\overline{\mathrm{r}}}\right]_{\mathrm{K}-1}+\left[\frac{\delta \mathrm{r}}{\overline{\mathrm{r}} \mathrm{k}}\right]_{\mathrm{K}}} \partial \mathrm{d}=\mathrm{G}_{\mathrm{K}-1} \delta \theta\left(\mathrm{T}_{\mathrm{K}-1}-\mathrm{T}_{\mathrm{K}}\right)
$$

as shown in Figure 3-9,

$$
\frac{\mathrm{M}_{\mathrm{K}}}{\Delta \mathrm{t}}+\sum \dot{\mathrm{m}}_{\mathrm{out}}=\frac{\mathrm{M}_{\mathrm{K}}}{\Delta \mathrm{t}}+\sum \dot{\mathrm{m}}_{\mathrm{in}}=\mathrm{f}(\delta, \theta)
$$

and

$$
\sum(\dot{\mathrm{m}} \hat{\mathrm{h}})_{\mathrm{in}}=\mathrm{g}(\delta, \theta)
$$

since the $\hat{h}_{\mathrm{in}}$ are (explicitly) known from previous time-step values.

For sensible energy changes, $\hat{h}_{k}=\hat{h}_{k}\left(T_{k}\right)$, thus, the set of algebraic equations for $\mathrm{KF}+1 \leq \mathrm{K} \leq \mathrm{KMX}$ involve nonlinear products of the (interim) variables $\delta, \theta, \mathrm{T}_{\mathrm{K}}$. These are replaced by Taylor Series approximations (i.e., are "linearized") to known values at a previous iteration; for example, 


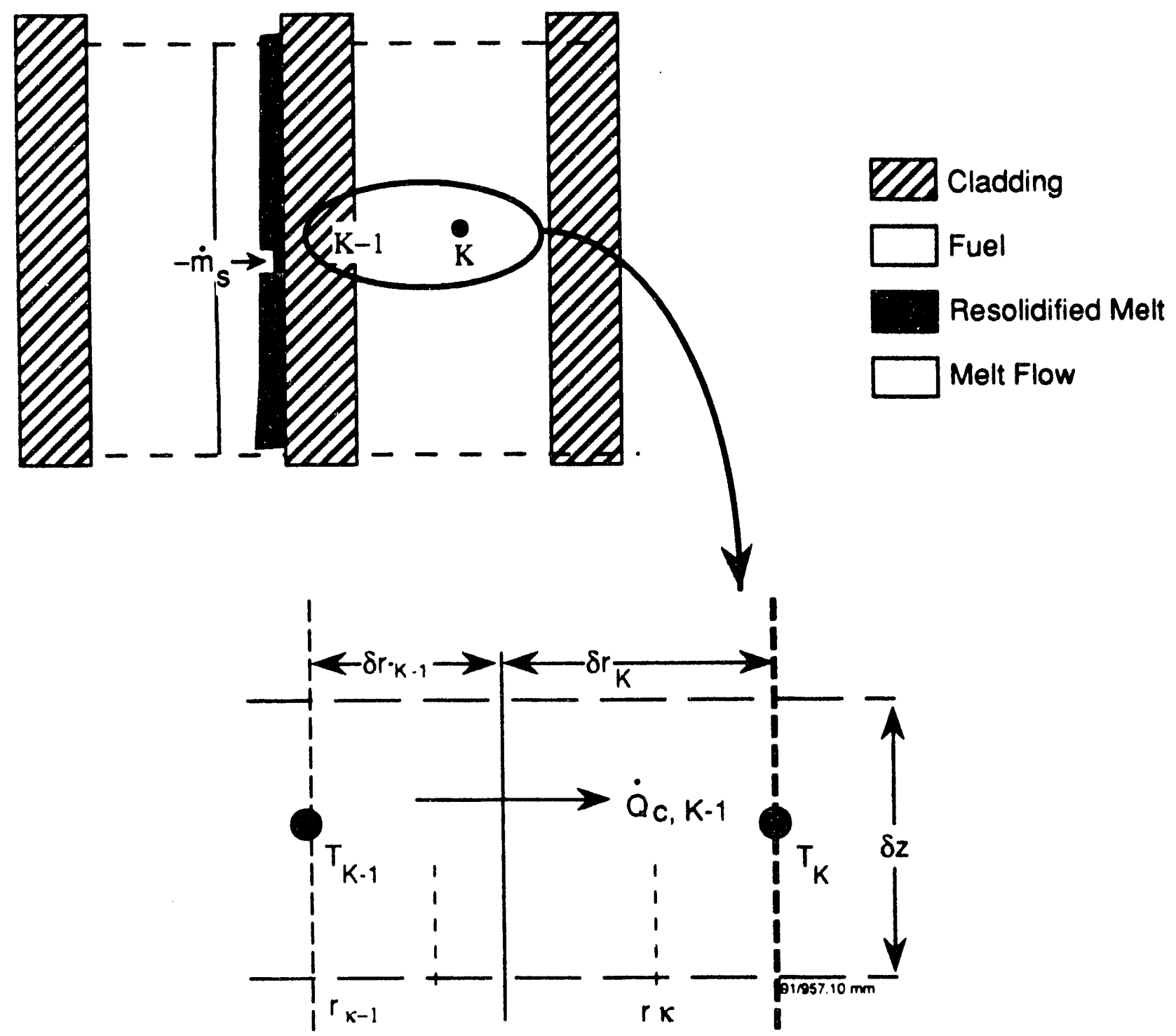

Figure 3-9. Nodalization of Stationary Substrate Layers 


$$
\delta \theta \mathrm{T}_{\mathrm{K}}=\left(\delta \theta \mathrm{T}_{\mathrm{k}}\right)^{\circ}+\left(\theta^{\circ} \mathrm{T}_{\mathrm{K}}^{0}\right)\left(\delta-\delta^{\circ}\right)+\left(\delta^{\circ} \mathrm{T}_{\mathrm{K}}^{0}\right)\left(\theta-\theta^{\circ}\right)+\left(\delta^{\circ} \theta^{\circ}\right)\left(\mathrm{T}_{\mathrm{K}}-\mathrm{T}_{\mathrm{k}}^{\mathrm{o}}\right)
$$

Assuming $\dot{\mathrm{Q}}_{\mathrm{c}, \mathrm{k}}=0$ at $\mathrm{K}=\mathrm{KMX}$ and linearizing terms,

$$
T_{K}=A_{K}^{0} T_{K-1}+B_{K}^{0} \delta+C_{K}^{0} \theta+D_{K}^{0}
$$

Applying successive substitution for $\mathrm{K}=\mathrm{KMX}, \mathrm{KMX}-1, \ldots ., \mathrm{KF}+1$,

$$
T_{K F+1}=A_{K F+1}^{\circ} T_{K F}+B_{K F+1}^{0} \delta+C_{K F+1}^{0} \theta+D_{K F+1}^{\circ}
$$

where, of course, the coefficients $A^{\circ}$ through $D^{\circ}$ contain details of the linearization, and $T_{K F}$ is the flow temperature (an implicit function of the flow enthalpy). Given Eq. (24), the final step in developing the interfacial boundary conditions is to reduce the expression to primitive variable form. In the absence of mass exchange:

$$
\theta=\alpha A_{1}+\beta
$$

and for leading/trailing edge nodes

$$
\delta=\delta^{*} \pm v_{\mathrm{z}, \mathrm{Im} \times / 2} \Delta t
$$

resulting in the form

$$
T_{K F+1}=A_{K F+1}^{\prime \prime} \hat{h}+B_{K F+1}^{\prime \prime} v_{z}+C_{K F+1}^{\prime \prime} A_{f}+D_{K F+1}^{\prime \prime}
$$

(For involvement of the inner heat structure, a similar result applies.) 
When mass exchange is occurring,

$$
T_{K P+1}=T_{1 S}
$$

of course; however, the overall problem is complicated by requirements for eliminating

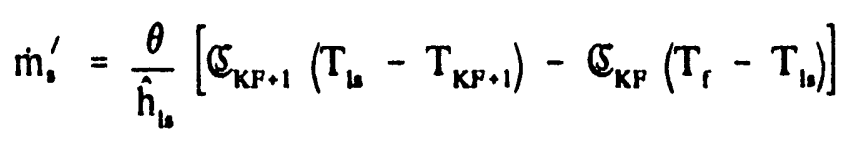

from the overall problem. For variable $\theta$, this is done by substituting:

$$
T_{K F+2}=A_{K F+2}^{0} T_{1,}+B_{K F+2}^{0} \delta+C_{K F+2}^{0} \theta+D_{K F+2}^{0}
$$

into Eq. (29), the resulting expression into Eq. (21), and re-linearizing the algebra, giving, in form,

$$
\theta=C_{A}^{o} A_{f}+C_{\delta}^{o} \delta+C_{T}^{o} T_{f}+C_{\theta}^{o}
$$

Equation (31) may then be used to reduce, for example, heat transfer to the interface

$$
\dot{\mathrm{Q}}_{s}^{\prime}=\boldsymbol{E}_{\mathrm{KF}} \theta\left(\mathrm{T}_{\mathrm{f}}-\mathrm{T}_{\mathrm{ls}}\right)
$$

to primitive form.

\subsubsection{Matrix Problem for Advancing Primitive Variables}

The governing equations for conservation of mass, momentum, and thermal energy within the relocating melt provide the basic methodology for advancing the overall analysis from one time step to the next. The methodology begins by substituting Eq. (6) in Eq. (7), giving: 


$$
\frac{\partial v_{z}}{\partial t}+\frac{1}{2} \frac{\partial v_{z}^{2}}{\partial z}=\left(g-\dot{g}_{d} v_{z}\right)-\frac{1}{\rho} \frac{\partial P}{\partial z}
$$

Two finite difference form of Eq. (33) are used. For nodes in which local flow behavior is subject to pressure gradients, the advective term is dropped and

$$
\frac{v_{2,1}-v_{2,1}^{*}}{\Delta t}=g-\dot{\delta}_{d, 1} v_{z, 1}-\frac{1}{\rho} \frac{P_{1}-P_{1}^{-}}{\delta_{1}}
$$

where,

$$
P_{1}^{-}=P_{1-1}+\frac{\gamma}{2} \rho\left(v_{z, 1-1}^{2}-v_{2,1}^{2}\right)
$$

and $\gamma=1$ for laminar flow and 2 for turbulent flow. Addition of a second unknown $\left(P_{1}\right)$ is compensated for by means of "downwind" expressions for enforcing conservation of mass:

$$
\rho v_{z, 1} A_{1}=\rho v_{2,1+1} A_{1+1}
$$

when node $I+1$ is also subject to pressure gradients, or, alternatively, for representing expansion into a free surface flow

$$
\mathrm{P}_{1}+\frac{\gamma_{1}}{2} \rho \mathrm{v}_{\mathrm{z}, \mathrm{l}}^{2}=\mathrm{P}_{\mathrm{e}}+\frac{\gamma_{1+1}}{2} \rho \mathrm{v}_{\mathrm{z}, \mathrm{l}+1}^{2}
$$

In Eq. (37), $P_{e}$ is the (known) ambient pressure. 
For nodes in which a free surface is subject to ambient pressure, the pressure gradient term is dropped and upwind differencing is applied to the advective term, giving:

$$
\frac{v_{z, 1}-v_{z, 1}}{\Delta t}+\frac{1}{2 \delta_{1}}\left(v_{z, 1}^{2}-v_{z, l-1}^{2}\right)=g-\dot{g}_{d, 1} v_{z, 1}
$$

The next step in the methodology is reformulation of Eqs. (6) and (8) into "conservative" form,

$$
\begin{aligned}
& \frac{d}{d t}(\rho A \delta)=\dot{m}_{1-1}-\dot{m}_{1}-\dot{m}_{1,1}^{\prime} \delta_{1} \\
& \frac{d}{d t}(\rho A \delta \hat{h})=(m \hat{h})_{1-1}-(\dot{m} \hat{h})_{1}
\end{aligned}
$$

which provide strict enforcement of mass/energy conservation. In difference form,

$$
\frac{1}{\Delta \mathrm{T}} \mathrm{A}_{1}=\frac{1}{\delta_{1}}\left[\frac{\mathrm{A}_{1} \cdot \delta_{1}^{*}}{\Delta \mathrm{t}}+\left(A v_{2}\right)_{1-1}-\left(A v_{2}\right)_{1}\right]-\frac{\dot{\mathrm{m}}_{3,1}^{\prime}}{\rho}
$$

where, $\dot{\mathrm{m}}_{3,1}^{\prime}$ is defined above in terms of $\mathrm{v}_{z, 1}, \mathrm{~A}_{1}$, and $\hat{h}_{1}$. Linearizing the first term on the right and collecting terms, the algebraic analogue of the continuity equation takes the form

$$
C_{1} A_{1}+C_{2} A_{1-1}+C_{3} v_{2,1}+C_{4} v_{2,1-1}+C_{5} \hat{h}_{1}=C_{7}
$$

Applying similar procedures to Eq. (40), there obtains

$$
D_{1} A_{1}+D_{2} A_{1-1}+D_{3} v_{4,1}+D_{4} v_{2,1-1}+D_{5} \hat{h}_{1}+D_{6} \hat{h}_{1-1}=D_{7}
$$


Applying Eqs. (34) through (38) and (41) for nodes I $=2,3, \ldots ., \mathrm{IMX}$ (incorporating, as appropriate, boundary conditions at $I=2$ and $I=I M X$, for example, $v_{z, 1} \hat{h}_{1}=v_{z, 1} A_{1}=0$ at the flow-packet trailing edge) gives the matrix form:

$$
A \Phi=B
$$

where,

$$
\Phi=\left[\begin{array}{c}
A_{2} \\
\vdots \\
A_{I M X} \\
v_{z, 2} \\
\vdots \\
v_{z, I M X} \\
\hat{h}_{2} \\
\vdots \\
\hat{h}_{I M X} \\
P_{2} \\
\vdots \\
P_{I M X}
\end{array}\right]
$$

Equation (44) is then solved by direct matrix inversion:

$$
\Phi=A^{-1} B
$$

\subsection{Organization of MELMRK 2.0 Relocation Modules}

MELMRK relocation modules for advancing implicit difference approximations to the relocating molten packet governing conservation equations from one relocation time step to the next 
together with calculations of thermal state of stationary substrate layers are organized as illustrated in Figure 3-10. For a given initial conditions of molten ejecta, MELMRK performs the following principal functions until the molten flow completely freezes during relocation processes or goes into the bottom of the assembly:

(I) For each relocation time step:

(1) Calls INITDT, which

(a) updates thermal/hydraulic states of relocating molten flow and thermal state of stationary substrate layers,

(b) provides magnitude of (retarding) drag forces on the contact surface(s), and

(c) gives estimates of leading and trailing edge locations.

(2) Calls QUENCH, which calculates the rate of steaming, owing to interaction of relocating molten flow packet with liquid coolant within the flow path.

(3) Calls DKPOWR, which calculates fission product decay heating within molten flow, if the fuel element is relocating.

(II) For each iteration within relocation time step:

(1) Calls SOLIDS, which provides coefficients of temperature for each stationary substrate sublayers.

(2) Calls XTHETA, which calculates contributions to peripheral changes of flow area due to flow side resistances and mass exchange if there is no azimuthal restriction. 


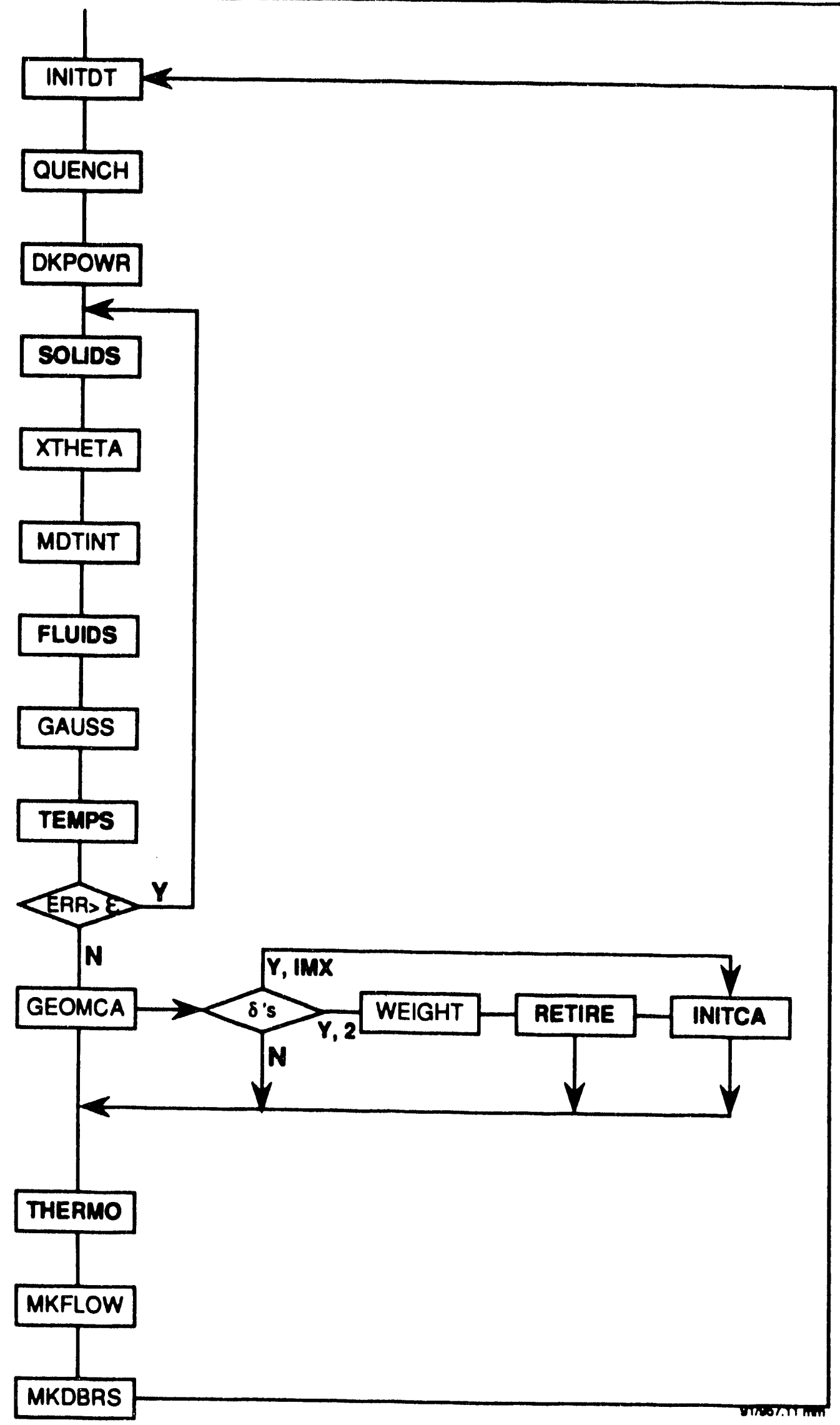

Figure 3-10. Flow Chart for MELMRK 2.0 Early Melt Relocation 
(3) Calls MDTINT, which supplies coefficients for mass exchange at the flow/substrate interface.

(4) Calls FLUIDS, which provides coefficients of set of partial difference equations for conservation of mass, momentum, and thermal energy for flow side problem.

(5) Calls GAUSS, which performs inversion of coefficient matrix to obtain the values of primitive variables, i.e., area, velocity, enthalpy, and pressure.

(6) Calls TEMPS, which advances temperature of stationary substrate layers.

(III) After the convergence of the flow side problem, for each relocating time step, MELMRK:

(1) Calls GEOMCA, which

(a) updates the geometry and positions of leading and trailing edges of relocating melt flow,

(b) calls WEIGHT to update weights within each control volume,

(c) calls RETIRE to update thermal conditions of the substrate layers as well as the fresh debris layer for the heatup code when the trailing edge divorces the control volume, and

(d) calls INITCA to initialize thermal/hydraulic conditions of flow and thermal conditions of substrate sublayers when the leading edge passes to a new control volume.

(2) Calls THERMO, which provides final state of substrate sublayers and updates the required control flags for the change of phase. 
(3) Calls MKFLOW, which updates fission product mass fractions within the relocating melt flow.

(4) Calls MKDBRIS, which updates fission products mass fractions within debris layer. 


\subsection{ILLUSTRATIVE RESULTS}

The MOD2 version of the MELMRK code has been extensively tested both for convergence characteristics of the numerical methodology and for automation of transitions between coexisting flow regimes during melt relocation. In addition, the code has been used to generate preliminary results for the meltdown behavior of Mark 31a assemblies under adiabatic : Mark $3 / 4$ conditions. Details of code testing and preliminary meltdown results for Mark 31a assemblies are discussed in the following subsections. The results of this section were obtained from an interim version of MELMRK. Code development funding was stopped prior to completing the final code version. Therefore, the interim version will not duplicate the results presented here.

\subsection{Convergence Behavior}

For testing the code numerics, a sample relocation case has been developed to obtain insights for the convergence behavior of both flow solver and substrate thermal analyzer. For these purposes, initial ' nditions of melt flow are assigned together with stationary substrate layer temperatures and riow cross-sectional areas along the pathway of the flow leading edge. Initially, the flow-packet is taken to be rivulet and the cross-sectional flow areas are assigned such that the flow undergoes transitions from rivulet to duct and duct to rivulet during downward relocation.

As discussed in Section 3.3, quasi-linearization of highly non-linear problem results in fast convergence of primitive variables. As seen from Table 4-1, flow primitive variables converge up to nine digits within three iterations. The primitive variables for each flow control volume are listed in the first column of the table (i.e., A, V, H, and P represent cross-sectional flow area, velocity, enthalpy, and pressure, respectively). The numbers next to the primitive variables denotes the flow control volumes; 2 is the trailing edge control volume, and $t$ is the leading edge.

Similar convergence behavior is also observed for the thermal response of adjacent substrate layers as shown in Table 4-2 for four different heatup axial nodes, $I_{H}$. The numbers in the 
Table 4-1. Convergence Behavior of Flow Primitive Variables

$$
\text { ITER }=3
$$

A2: $1.632958842511560 E-004$

A3: $\quad 4.505464668521013 E-005$

A4: $\quad 4.289834937764821 E-005$

A5: $\quad 3.468904443094273 E-005$

V2: $\quad 2.01003549445353$

V3: $\quad 2.04757982170442$

V4: $\quad 1.91666103087286$

V5: $\quad 1.89110636006094$

H2: 1157595.36449444

H3: 1157530.80696027

H4: $\quad 1157509.82629009$

H5: 1157503.74100284

P2: $\quad 144830.000000000$

P3: $\quad 144126.763646276$

P4: $\quad 144830.000000000$

P5: $\quad 144830.000000000$
ITER $=4$

1.6329588428875307E-004

$4.505464668520971 E-005$

4.289834937758843E-005

3.468904093948962E-005

2.01003549442234

2.04757982169393

1.91666103086942

1.89110636683314

1157595.36449443

1157530.80696026

1157509.82629009

1157503.74100385

144830.000000000

144126.763646316

144830.000000000

144830.000000000 
Table 42. Convergence Behavior of Stationary Substrate Layer Temperatures and Total Freezing Rate at the Leading Edge Control Volume

TTER = $3 \quad$ TTER $=4$

SUBSTRATE TEMPERATURE DISTRIBUTION

$(2,1,6): \quad 404.589569157647$

$(2,1,7): \quad 425.500929424247$

$(2,1,8): \quad 927.519893197988$

$(2,1.9): \quad 932.900000000000$

$(2,1,10): \quad 933.030541050898$

$(2,1,11): \quad 932.900000000000$

$(2,1,12): \quad 929.742226454215$

$(2,1,13): \quad 607.831943122289$

$(2,1,14): \quad 597.976539264680$

$(3,1,6): \quad 403.456949307631$

$(3,1,7): \quad 424.690400127420$

$(3,1,8): \quad 924.771910126422$

$(3,1,9): \quad 932.900000000000$

$(3,1,10): \quad 932.958489942609$

$(3.1 .11): \quad 932.900000000000$

$(3,1,12): \quad 930.417613141587$

$(3,1,13): \quad 608.529109538022$

$(3,1,14): \quad 598.239722524054$

$(4,1,10): \quad 932.935074024942$

$(4,1,11): \quad 932.900000000000$

$(4,1,12): \quad 929.651849932492$

$(4,1,13): \quad 604.756366730613$

$(4,1,14): \quad 596.134857065328$

$(5,1,10): \quad 932.928281812338$

(5.1.11): $\quad 932.900000000000$

$(5,1.12): \quad 908.549730885009$

$(5,1,13): \quad 601.833950336915$

$(5,1,14): \quad 594.760861561368$

MOOTW = 0.228787502580750
$I_{H}=14$

404.589568892695 425.500927264788

927.519873811530

932.900000000000

933.030540730387

932.900000000000

929.742220783826

607.831942055423

597.976539160162

$I_{H}=13$

403.456949307631

424.690400127420

924.771910126422

932.900000000000

932.958489911010

932.900000000000

930.417613141587

608.529109538022

598.239722524054

$I_{H}=12$

932.935073984480

932.900000000000

929.651849932492

604.756366730613

596.134857065328

$I_{H}=11$

932.928282370371

932.900000000000

908.549740559767

601.833953506611

594.760861920073

0.928787124149469 
parentheses given in the first column of the table represents, respectively, control volume of relocating flow, azimuthal nodalization (region adjacent to flow), and the radial nodalization; radial node 10 is the flow node. In addition, the convergence behavior of total freezing rate at the leading edge node is also given in the table.

\subsection{Flow Transitions}

The options that are available for treating coexisting flow regimes, as well as dynamic transitions between flow regimes, have been subjected to extensive testing to confirm logic capabilities and to exercise all elements of the relocation routines shown in Figure 3-10. Illustrative results for treatment of coexisting flow regimes are presented in Figure 4-1, where a rivulet (represented by horizontal wavy lines) is flowing downwards in contact with heatup nodes at axial levels 15 through 12 (relocation nodes 2 through 4 ) for elapsed times ranging from $0.1 \mathrm{~s}$ to $0.35 \mathrm{~s}$. The progression of the rivulet through the reduced area section at $I_{H}=13$ (owing to previously refrozen melt-note the $\theta=2 \pi-40^{\circ}$ portion of the annulus) exhibits (characteristic) flow spreading in the node above ( $\theta$ approaches $157^{\circ}$ as $t$ approaches $0.35 \mathrm{~s}$ ). A second feature of the modeling capability is depicted at $I_{H}=12$ for $t=0.35 \mathrm{~s}$, where the exiting flow from node 13 is presumed to form a minimum area rivulet on the concave side of flow channel. (Above the "blockage," the rivulet maintains its initial configuration wherein, say, molten fuel has been ejected locally into the flow channel in contact with both inner and outer assembly tubes.)

Illustrative results for transitions between flow regimes are given in Figure 4-2 for case in which melt is flowing into a fully blocked cell in contact with the outer fuel tube at $t=0.065 \mathrm{~s}$. Owing to blockage, the rivulet experiences spreading in both the inwards radial direction as well as azimuthally, resulting in contact with the inner heat structure at $t=0.135 \mathrm{~s}$. (At this time, the flow node would have been removed from further participation in the relocation analysis if its azimuthal extent had been constrained, i.e., $\theta=\theta_{\max }$-this is done by decrementing IMX, followed by a search for an alternative pathway for the flow leading edge, say, transverse flow into an adjacent flow channel or filling of the node above.) Of further interest is the immediate involvement of a second heat structure following interaction with the inner radial surface (note the thermal wave within fuel/clad zones for $2.0<\mathrm{r}<3.0 \mathrm{~cm}$ ). 


\section{$\mathbf{I}_{\mathbf{H}}$}

$$
\mathbf{t}=0.15 \text { s }
$$

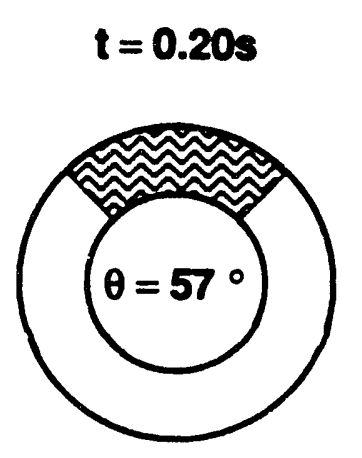

$\mathbf{t}=\mathbf{0 . 3 5 s}$

15
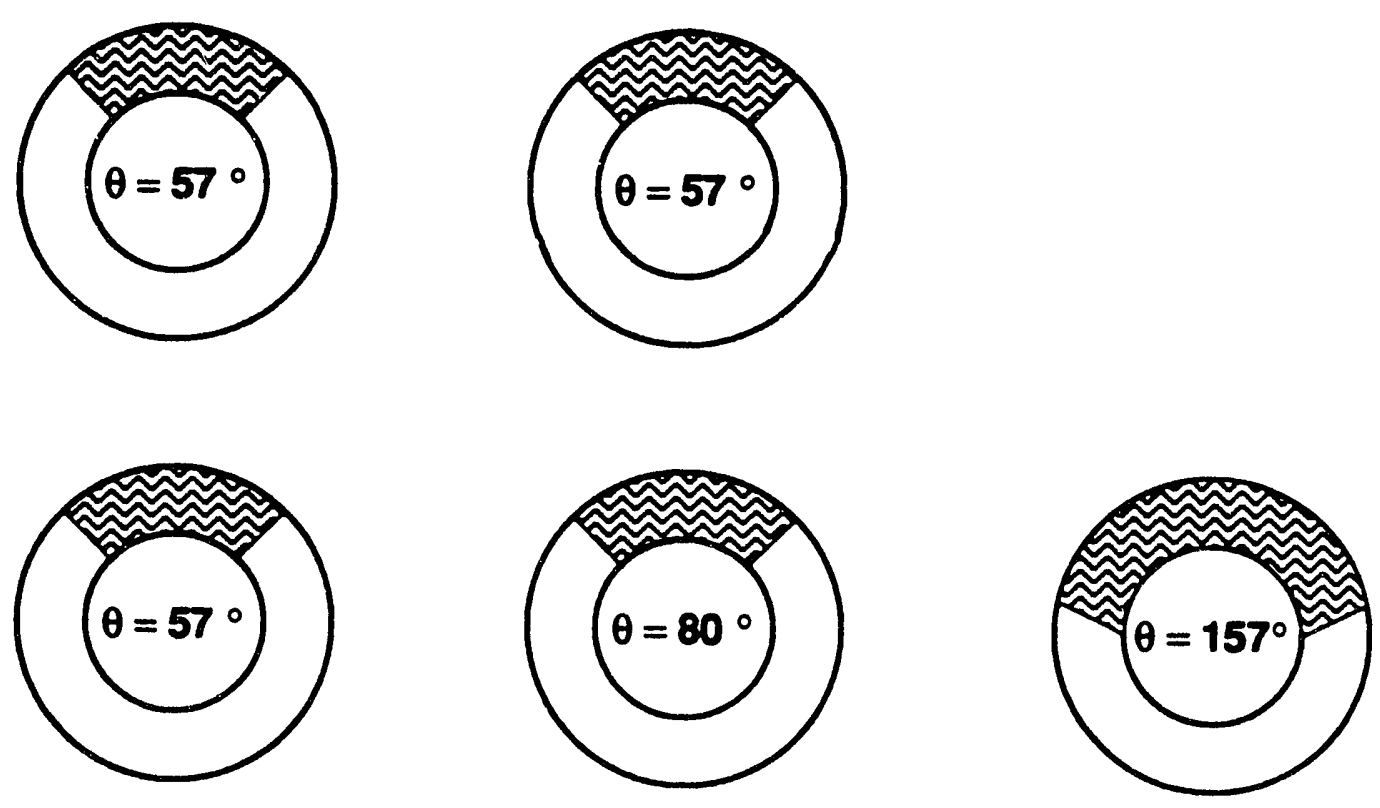

14
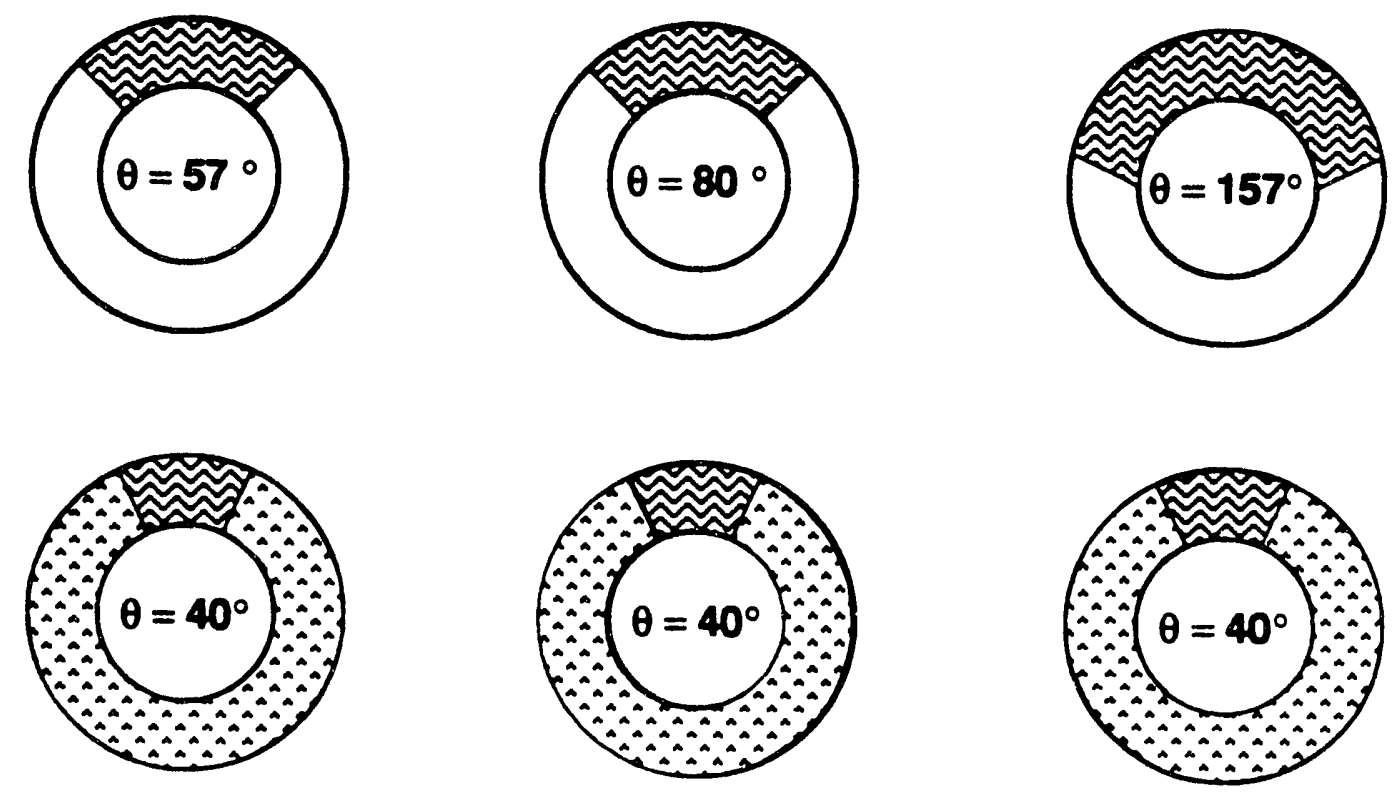

12
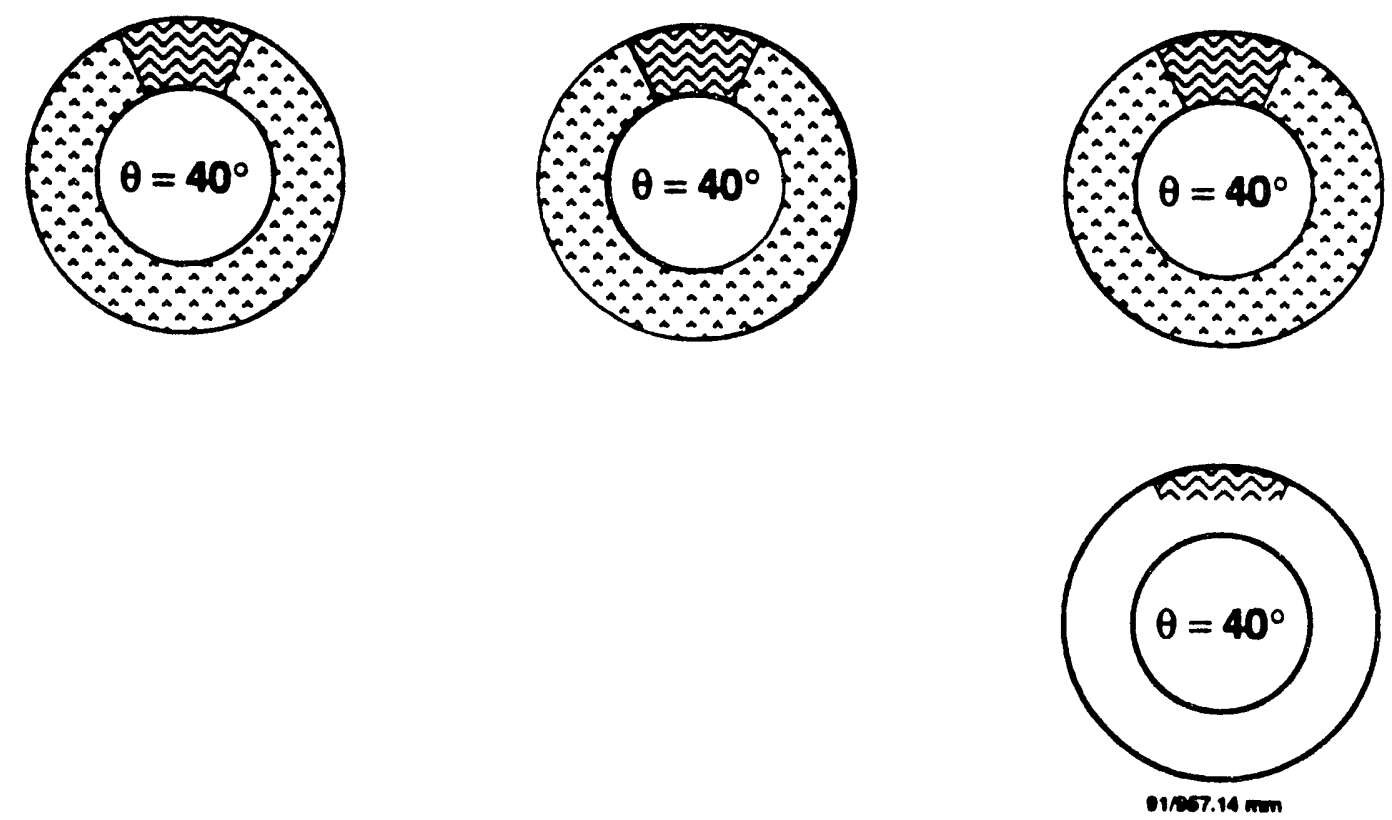

Figure 41. Code Predictions of Coexisting Flow Regimes for Sample Relocation Problem 


$$
t=.065
$$

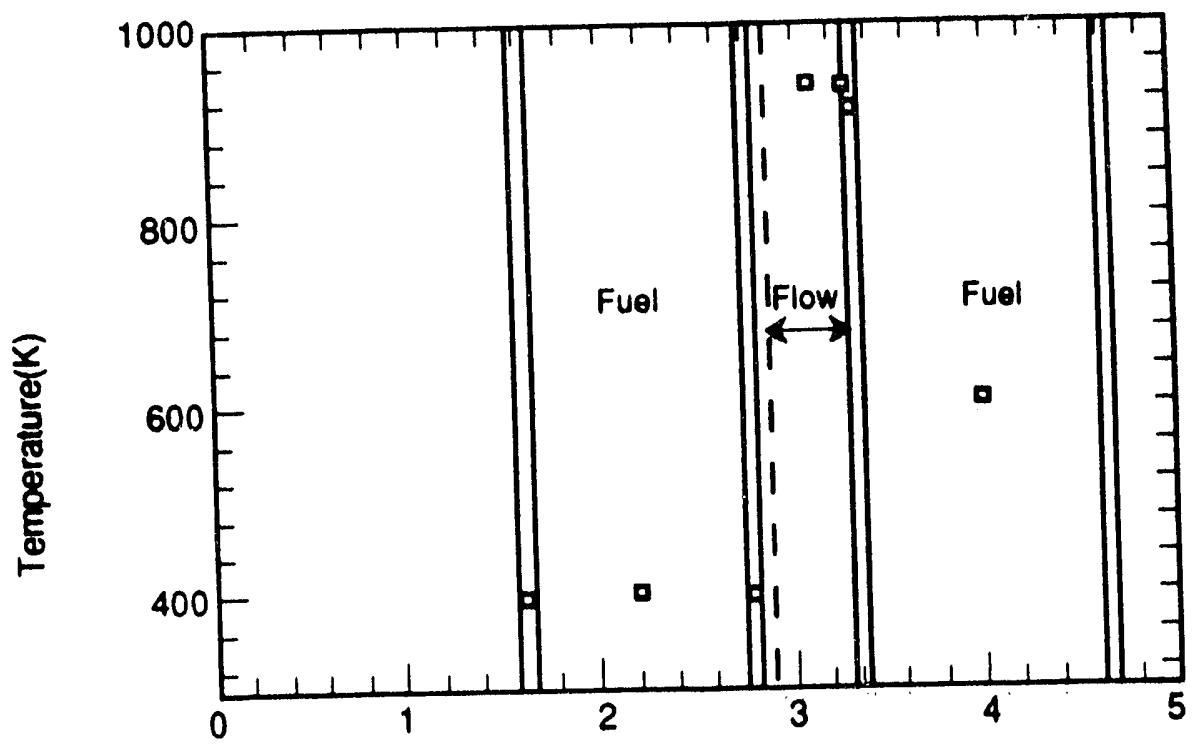

Distance From Center of Fuel Assembly $(\mathrm{cm})$

$t=135$

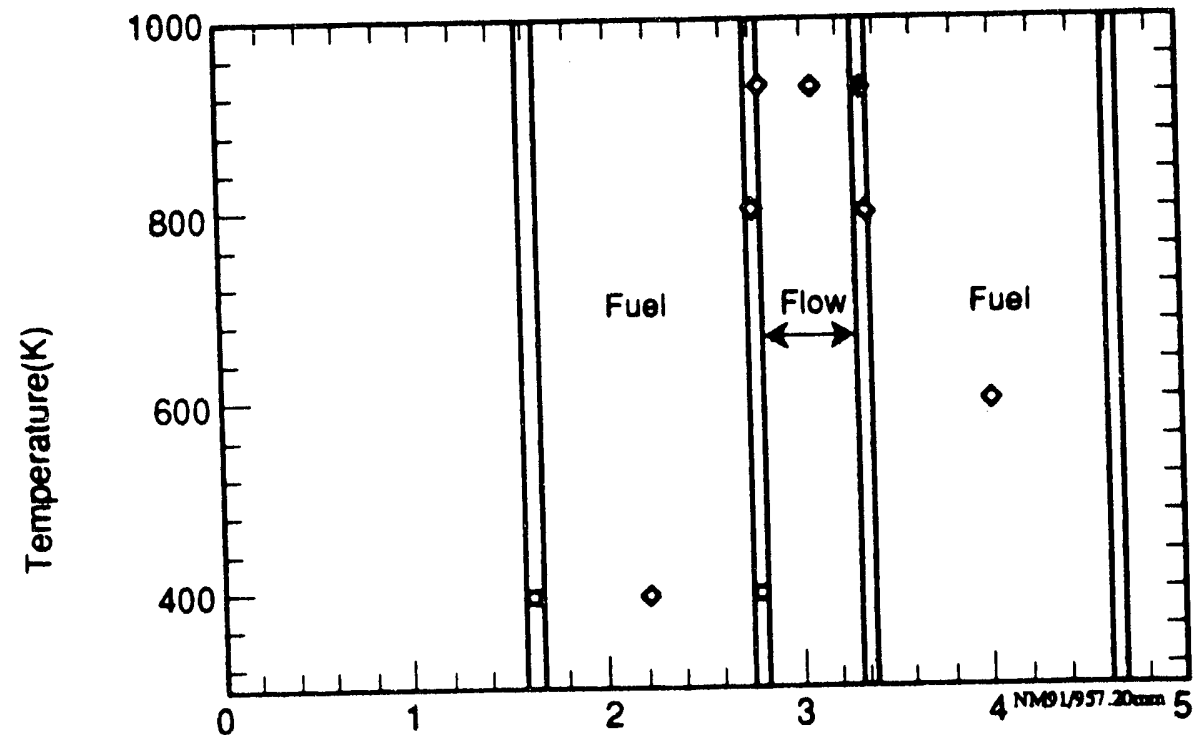

Distance From Center of Fuel Assembly(cm)

Figure 4-2. Dynamic Flow Transitions Within Dead-Ended Cell 
A final example of code options for treating flow regime behavior is illustrated in Figure 4-3, where a vanishingly thin stream of relocating melt exhibits approach to zero velocity, resulting in its total freezing between times $t$ and $t+\epsilon$.

\subsection{Mark 31a Meltdown}

An illustrative calculation for demonstrating overall capabilities of relocation modeling in MELMRK 2.0 was performed to test code options. Illustrated here is the progression of assembly meltdown for adiabatic heatup of Mark 31 a assemblies within the innermost power region (see Figures 4-4 and 4-5). In Figures 4-4 and 4-5, inner/outer sleeve housings, refrozen melt flow, cladding and fuel are represented by vertical lines $(|| \mid)$, pound signs (\#\#), opening/ closing brackets ([ ]), and periods (:::), respectively. Associated values of release fractions for volatile fission products are displayed in Figure 4-6. 

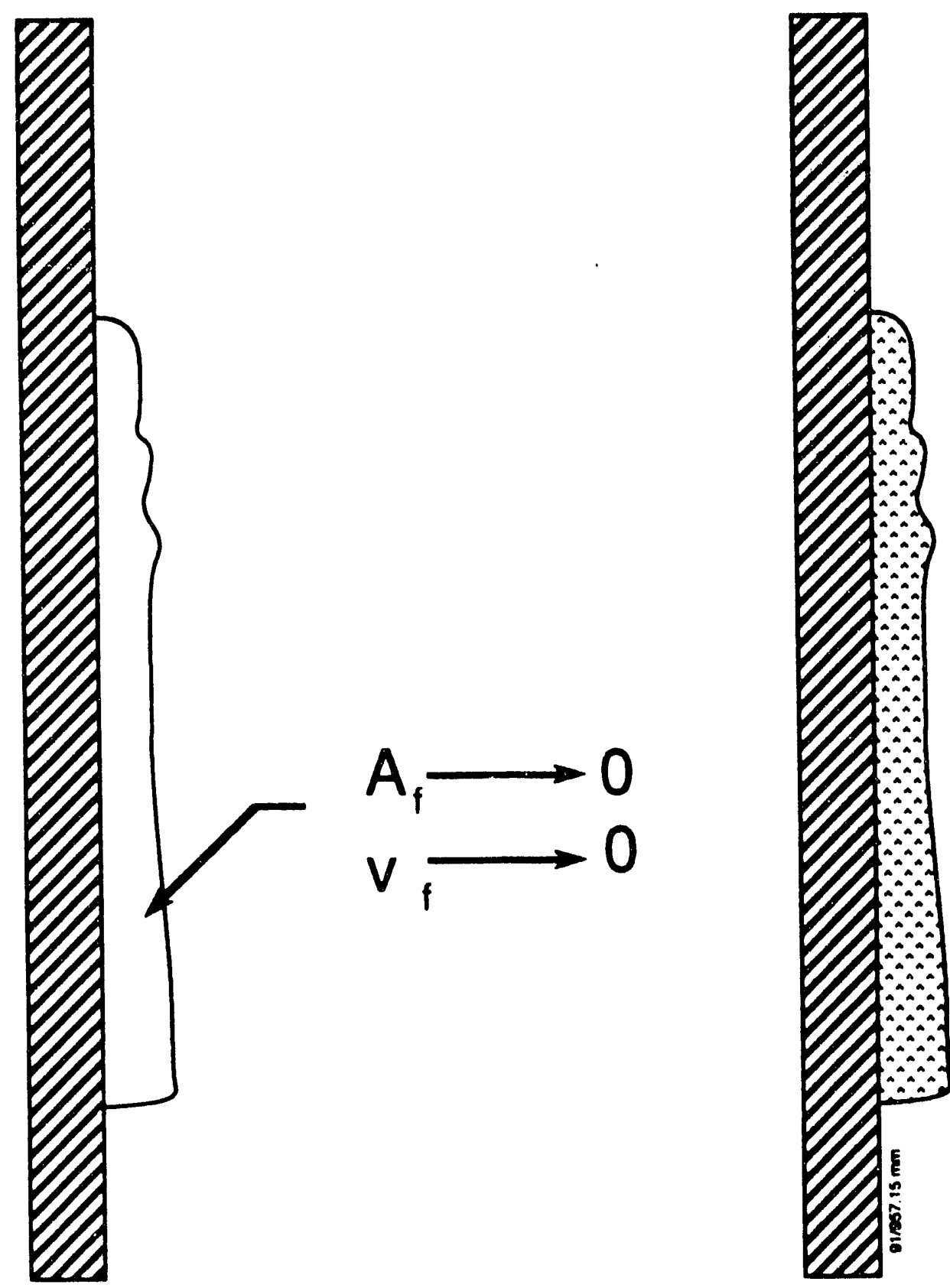

$t+\varepsilon$

Figure 4-3. Illustration of Vanishingly Thin Flow Stream Resolidification 


\section{MARK 31 MELTDOWN BEHAVIOR} TIME $=$ 500. SEC

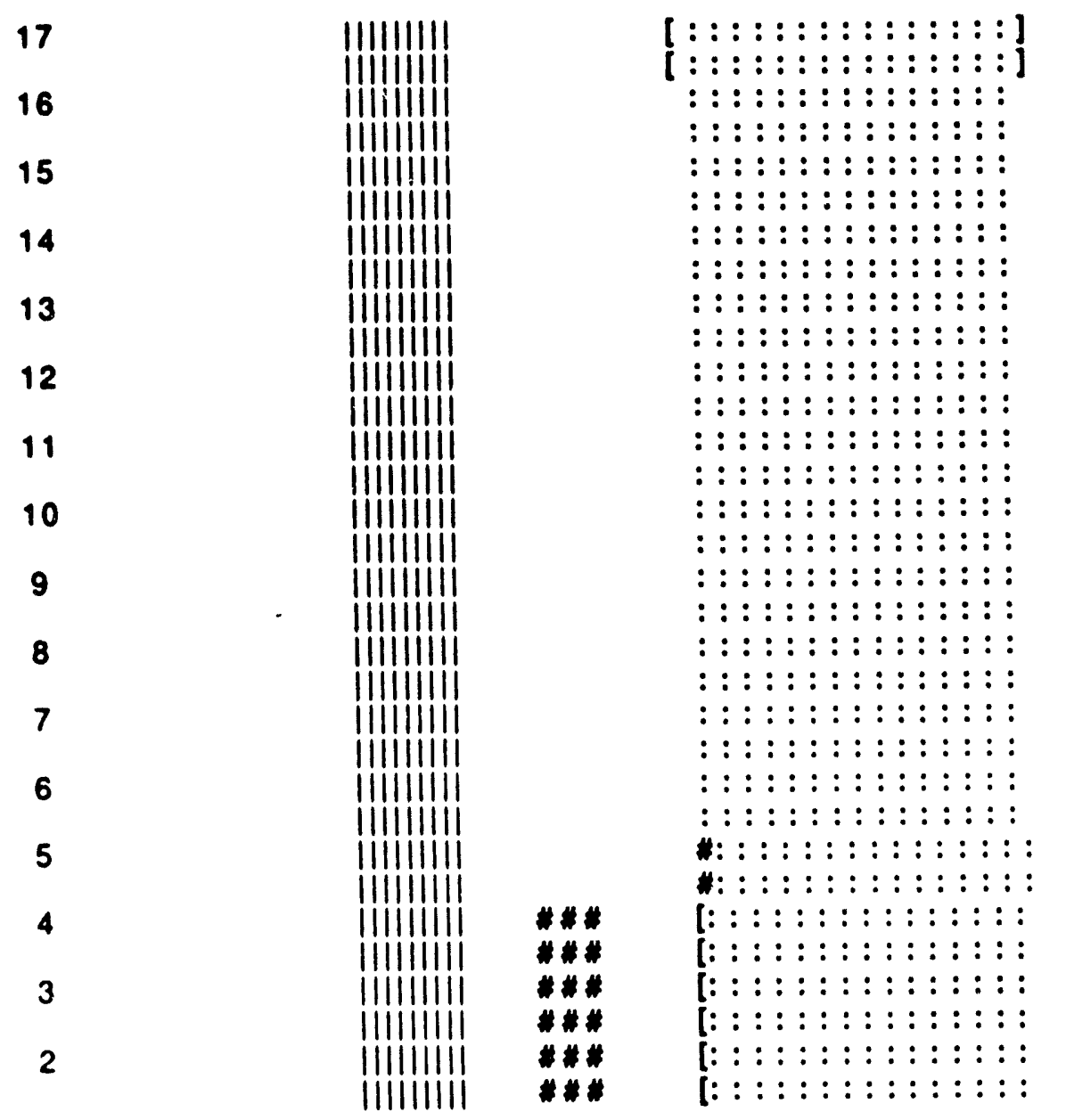

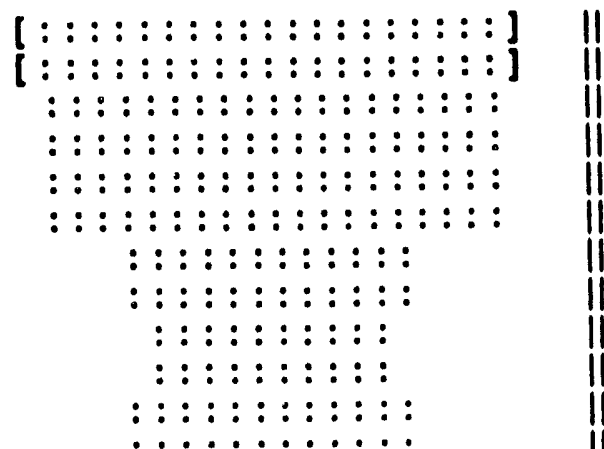

$:::::::::::$ : :

: : : : : : : : : : : :

$::::::::::::::$

$:::::::::::::$

: : : : : : : : : : : :

: : : : : : : : : : : :

$:::::::::::::$ :

: : : : : : : : : : : :

: : : : : : : : : : : :

: : : : : : : : : :

: : : : : : : : : :

$:::::::::::$

: : : : : : : : : :

$::::::::::::$ :

$:::::::::::::$

: : : : : : : : : : : :

: : : : : : : : : : : :

$:::::::::::::::$ :

$:::::::::::::::$ औ

$::::::::::::::::::::$ ||

$\because ! A$

Figure 4-4. Relocation of Mark 3a Assembly Hardware Under Adiabatic Heatup at $\mathbf{t}=\mathbf{5 0 0}$ Seconds 
MARK 31 MELTDOWN BEHAVIOR

TIME $=820$. SEC

\begin{tabular}{|c|c|c|c|c|}
\hline 17 & & \|\|\|\|\|\| & [ : : : : : : : : : : : : : : : : ] & {$[::::::::::::::::::::::::$ : } \\
\hline \multirow[t]{3}{*}{16} & & 11111111 & {$[:::::::::::::::::::$ ] } & 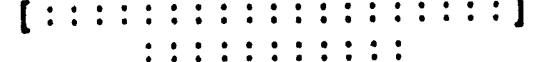 \\
\hline & & IIIIIIIII & $\begin{array}{l}\text { : : : : : : : : : : : : : : : : } \\
\text { : : : : : : : : : : : : : : : }\end{array}$ & $\begin{array}{l}\text { : : : : : : : : : : : } \\
\text { : : : : : : : : : : }\end{array}$ \\
\hline & & IIIIIIII & $:::::::::$ & $::::$ \\
\hline 15 & & iiliiiiii & $::::::::$ & $::::$ \\
\hline \multirow{2}{*}{14} & & |||||||| $\mid$ & $::$ & $::$ \\
\hline & & $\|||||||||$ & $::$ & $::$ \\
\hline 13 & & |I!IIIII! & $:::$ & $::$ \\
\hline \multirow[t]{2}{*}{12} & & IIIIIIIII & $\begin{array}{l}::: \\
::::\end{array}$ & $\begin{array}{l}:: \\
\vdots:\end{array}$ \\
\hline & & IIIIIIIII & $::::$ & $\begin{array}{l}: \\
: \\
:\end{array}$ \\
\hline \multirow[t]{2}{*}{11} & & $11111 \| 111$ & $:::$ & $\vdots \vdots$ \\
\hline & & ||I||||||| & $:::$ & $::$ \\
\hline 10 & & $\|I\| I\|I\|$ & $:: \vdots$ & $::$ \\
\hline \multirow[t]{2}{*}{9} & & IIIIIIIII & $\because::$ & $\begin{array}{l}:: \\
::\end{array}$ \\
\hline & & IIIIIIIII & $::$ & $\begin{array}{l}\vdots: \\
:\end{array}$ \\
\hline 8 & & 111111111 & $::::$ & $\vdots:$ \\
\hline \multirow{2}{*}{7} & & $11|1|||||$ & $::::$ & $::$ \\
\hline & & \|\|\|\|\|\| & $::$ & $::$ \\
\hline \multirow[t]{2}{*}{6} & & IIIIIIII & $\vdots:$ & $\begin{array}{l}:: \\
: \vdots\end{array}$ \\
\hline & & \|IIIIII & $\vdots:$ & : \\
\hline \multirow{2}{*}{5} & & $\# \# \# \# \#$ & $::$ & $\vdots:$ \\
\hline & 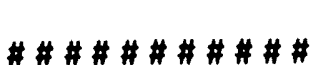 & \#\#\#\#\# & $::$ & $::$ \\
\hline 4 & 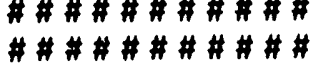 & $\|\Pi\| \Pi \|$ & $\vdots:$ & $::$ \\
\hline \multirow[t]{2}{*}{3} & $\# \# \# \# \# \# \# \# \#$ \# \# & $\lim _{\forall \rightarrow t}$ & $\vdots:$ & $\begin{array}{l}:: \\
\vdots:\end{array}$ \\
\hline & & $\# \# \# \#$ & $\vdots \vdots$ & $\begin{array}{l}: \vdots \\
\vdots\end{array}$ \\
\hline \multirow[t]{2}{*}{2} & & & $:::::::$ & $::$ \\
\hline & & & $:::::$ & $::$ \\
\hline
\end{tabular}

bit:

Figure 45. Relocation of Mark 31:a Assembly Hardware Under Adiabatic Heatup at $t=820$ Seconds 


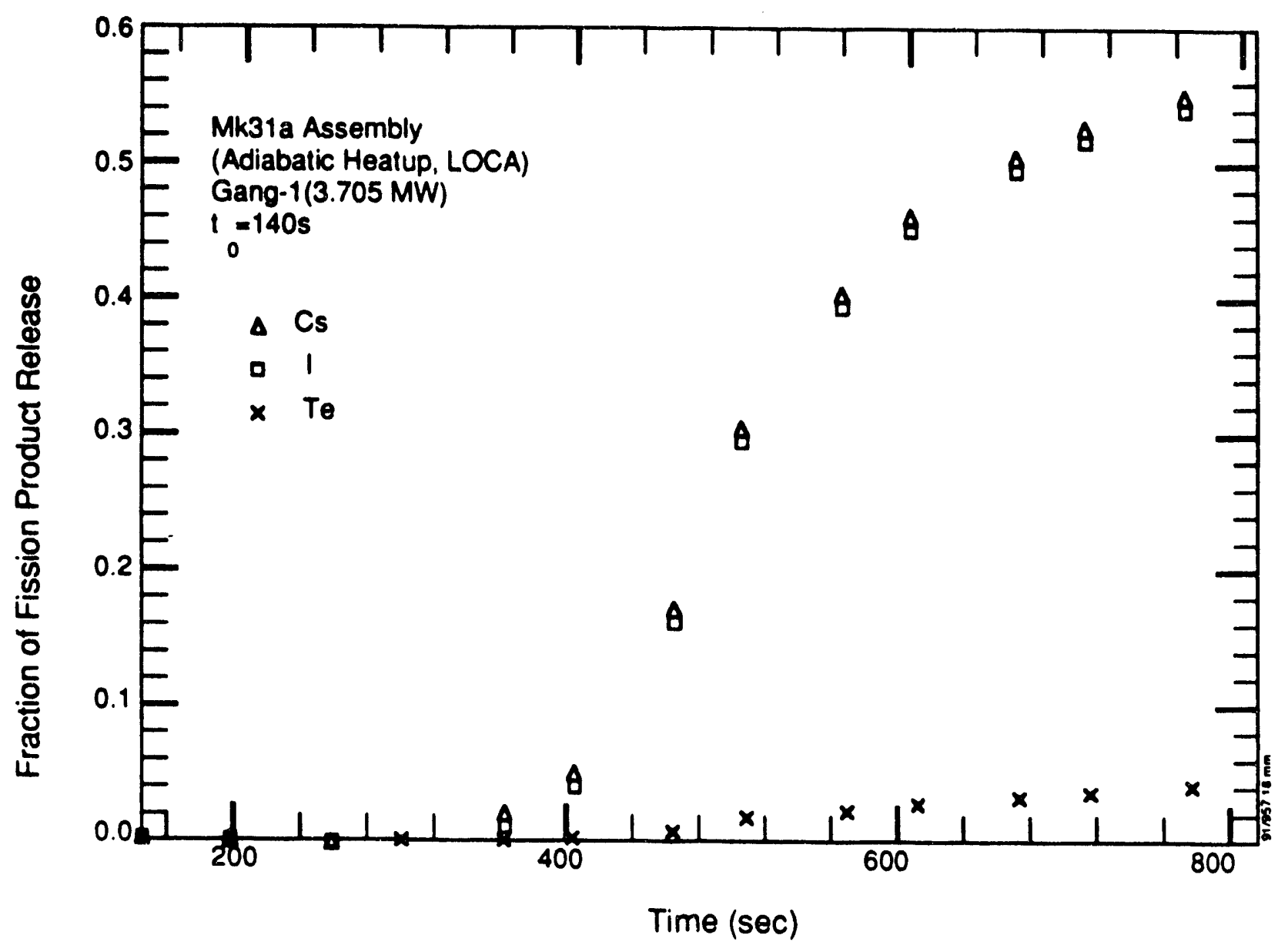

Figure 4-6. Fission Product Release During Adiabatic Heatup of Mark 31q. Assemblies 


\subsection{RECOMMENDED FUTURE WORK}

At the time the work was stopped, the authors were developing a preprocessing code to allow extensive user interactions. This would have allowed a more complete investigation of the melt progression options embedded in the code. 


\subsection{REFERENCES}

1. Denny, V., and A. Mertol, "Early Melt Relocation," A Methodology to Examine InVessel Phenomena for Use in the SRS Reactor Level 2 Probabilistic Risk Assessment, compiled by C. N. Amos and K. A. Williams, pp. 3.2-1 through 3.2-53, February 1988. 


\section{APPENDIX A: INPUT DESCRIPTION}

MELMRK uses the FORTRAN namelist system for input. The subroutine INTMRK.FOR contains the initial data in namelist form. Table A-1 gives a complete listing of the variables in INTMRK.FOR. Input can be changed without modifying INTMRK.FOR by making modifications to SRPIN.DAT. Table A-2 is a listing of SRPIN.DAT, the input used to run this case. The input geometry used by this version of MELMRK is specific to a Mark 3 la fuel assembly. 


\section{Table A-1. Variable Definition}

\section{NAMELIST FLOW}

$\begin{array}{ll}\text { MWTD20 } & =\text { Molecular weight of deuterium }(\mathrm{kg} / \mathrm{kg} \cdot \mathrm{mole}) \\ \text { MWTD2 } & =\text { Molecular weight of } D_{2} \text { gas }(\mathrm{kg} / \mathrm{kg} \cdot \mathrm{mole}) \\ \text { RHOLIO } & =\text { Density of liquid deuterium }\left(\mathrm{kg} / \mathrm{m}^{3}\right) \\ \text { CPLIO } & =\text { Specific heat of liquid deuterium }(\mathrm{J} / \mathrm{kg}-\mathrm{K}) \\ \text { THCL1O } & =\text { Thermal conductivity of liquid deuterium }(\mathrm{W} / \mathrm{m}-\mathrm{K}) \\ \text { VISLIO } & =\text { Viscosity of liquid deuterium }\left(\mathrm{m}^{2} / \mathrm{s}\right) \\ \text { MDTBOT } & =\text { Mass flow rate to flow channel from bottom }(\mathrm{kg} / \mathrm{s}) \\ \text { MDTTOP } & =\text { Mass flow rate to flow channel from top }(\mathrm{kg} / \mathrm{s}) \\ \text { CPD20 } & =\text { Average specific heat of deuterium }(\mathrm{J} / \mathrm{kg}-\mathrm{K}) \\ \text { CPD2 } & =\text { Average specific heat of } \mathrm{D}_{2} \text { gas }(\mathrm{J} / \mathrm{kg}-\mathrm{K})\end{array}$

2. NAMELIST GEOM

$\begin{array}{ll}\text { KMAX } & =\text { Total number of layers } \\ \text { LMAX } & =\text { Number of tubes in the assembly } \\ \text { RFLOW } & =\text { Inner radii of tubes (in) } \\ \text { DELCL } & =\text { Cladding thickness (in) } \\ \text { DELFT } & =\text { Thickness of tube (in) } \\ \text { IMIN } & =\text { Lowermost axial zone in dried out region of core } \\ \text { IMAX } & =\text { Uppermost axial zone in core nodalization } \\ \text { HCORE } & =\text { Height of the core (m) } \\ \text { KDBA } & =\text { Indices for inner debris layer } \\ \text { KCLA } & =\text { Indices for inner cladding } \\ \text { KOXA } & =\text { Indices for inner oxide layer } \\ \text { KFTA } & =\text { Indices for fuel layer } \\ \text { KFTB } & =\text { Indices for outer fuel layer (currently is not used) } \\ \text { KOXB } & =\text { Indices for outer oxide layer } \\ \text { KCLB } & =\text { Indices for outer cladding } \\ \text { KDBB } & =\text { Indices for outer debris layer } \\ \text { PITCH } & =\text { Pitch (inches) } \\ \text { XRFDBA } & =\text { Reference node for inner debris }\end{array}$




\section{Table A-1. Variable Definition}

\begin{tabular}{|c|c|c|}
\hline XRFOXA & $=$ & Reference node for inner oxide layer \\
\hline XRFCLA & $=$ & Reference node for inner cladding \\
\hline XRFFTA & $=$ & Reference node for fuel (central node in the fuel tube) \\
\hline XRFOXB & $=$ & Reference node for outer oxide layer \\
\hline XRFCLB & $=$ & Reference liquid mass fraction for outer cladding \\
\hline XRFDBB & $=$ & Reference liquid mass fraction for outer debris \\
\hline NSTPCR & $=$ & Printing frequency \\
\hline XRFFTB & $=$ & Reference node for fuel \\
\hline
\end{tabular}

\section{NAMELIST PARAMS}

$\begin{array}{ll}\text { PCORE } & =\text { Pressure (MPa) at the saturation temperature (TSAT) } \\ \text { RUNIV } & =\text { Universal gas constant (J/kg-mole-K) } \\ \text { PIE } & =\text { constant } \\ \text { TSAT } & =\text { Saturation temperature (K) } \\ \text { NDBA } & =\text { Indices for ordering inner debris species } \\ \text { NDBB } & =\text { Indices for ordering outer debris species } \\ \text { ZERO } & =\text { Smallest number } \\ \text { TFAIL } & =\text { Temperature at which cladding in Mark } 168 \text { fuel assembly fails } \\ \text { TOXID } & =\text { Temperature at which oxidation of metals starts (K) } \\ \text { DTCA } & =\text { Time step for relocation code (s) } \\ \text { ITERMX } & =\text { Maximum iteration } \\ \text { RFERCA } & =\text { Maximum error used in mass-exchange calculations } \\ \text { KTOTCA } & =\text { Total number of radial nodes used in relocation code } \\ \text { MLMIN } & =\text { Mass fraction of liquid phase } \\ \text { THIKMN } & =\text { Minimum thickness used in relocation code (m) } \\ \text { KFLW } & =\text { Indices for flow node used in relocation code } \\ \text { ORXO2 } & =\text { Heat of reaction for oxidation }(\mathrm{J} / \mathrm{kg}) \\ \text { AMINCA } & =\text { Smallest area used in relocation code (m²) } \\ \text { ZEROAG } & =\text { Smallest allowable gas flow area }\left(\mathrm{m}^{2}\right) \\ \text { NSTPMX } & =\text { Maximum calculational time step } \\ \text { SIGMA } & =\text { Stefan-Boltzmann constant }\left(W / \mathrm{m}^{2}-\mathrm{K}^{4}\right) \\ & \end{array}$




\section{Table A-1. Variable Definition}

$\begin{array}{ll}\text { DZCAMN } & =\text { Residual height used in relocation code }(\mathrm{m}) \\ \text { ICNDLE } & =\text { Controls call to relocation code }(=0 \text { means skip relocation code) } \\ \text { ITEROX } & =\text { Maximum iteration for oxidation kinetics } \\ \text { RFEROX } & =\text { Maximum error for kinetics calculations } \\ \text { EPSRAD } & =\text { Emissivity } \\ \text { NSTPCR } & =\text { Printing frequency } \\ \text { NSTPLT } & =\text { Plotting frequency } \\ \text { TMPSUB } & =\text { Initial structure temperature }(\mathrm{K}) \\ \text { TMOD } & =\text { Moderator water temperature }(\mathrm{K}) \\ \text { TBOTIN } & =\text { Injected water temperature to the flow channels }(\mathrm{K}) \\ \text { ASEFF } & =\text { Effective surface area fraction used to simulate rivulet flow } \\ \text { VBOTIN } & =\text { Velocity of injected water to the flow channels }(\mathrm{m} / \mathrm{s}) \\ \text { TIMBOT } & =\text { Time at which injection of water started }(\mathrm{s}) \\ \text { GEE } & =\text { Acceleration of gravity }\left(\mathrm{m} / \mathrm{s}^{2}\right) \\ \text { XNUFLW } & =\text { Viscosity }\left(\mathrm{m}^{2} / \mathrm{s}\right) \\ \text { VELZERO } & =\text { Initial velocity of relocating corium }(\mathrm{m} / \mathrm{s})\end{array}$

4. NAMELIST PROPIC

$\begin{array}{ll}\text { CPOX } & =\text { Specific heat of oxide }(\mathrm{J} / \mathrm{kg}-\mathrm{K}) \\ \text { CPCL } & =\text { Specific heat of cladding }(\mathrm{J} / \mathrm{kg}-\mathrm{K}) \\ \text { CPTR } & =\text { Specific heat of target material }(\mathrm{J} / \mathrm{kg}-\mathrm{K}) \\ \text { CPFR } & =\text { Specific heat of fuel }(\mathrm{J} / \mathrm{kg}-\mathrm{K}) \\ \text { NSOLIC } & =\text { Number of structural species } \\ \text { HMLTOX } & =\text { Heat of fusion for oxide }(\mathrm{J} / \mathrm{kg}) \\ \text { HMLTCL } & =\text { Heat of fusion for cladding }(\mathrm{J} / \mathrm{kg}) \\ \text { HMLTTR } & =\text { Heat of fusion for target material }(\mathrm{J} / \mathrm{kg}) \\ \text { HMLTFR } & =\text { Heat of fusion for fuel }(\mathrm{J} / \mathrm{kg}) \\ \text { RHOOX } & =\text { Density of oxide }\left(\mathrm{kg} / \mathrm{m}^{3}\right) \\ \text { RHOCL } & =\text { Density of cladding }\left(\mathrm{kg} / \mathrm{m}^{3}\right) \\ \text { RHOTR } & =\text { Density of target material }\left(\mathrm{kg} / \mathrm{m}^{3}\right) \\ \text { RHOFR } & =\text { Density of fuel }\left(\mathrm{kg} / \mathrm{m}^{3}\right)\end{array}$




\section{Table A-1. Variable Definition}

$\begin{array}{ll}\text { THCOX } & =\text { Thermal conductivity of oxide }(\mathrm{W} / \mathrm{m}-\mathrm{K}) \\ \text { THCCL } & =\text { Thermal conductivity of cladding }(\mathrm{W} / \mathrm{m}-\mathrm{K}) \\ \text { THCTR } & =\text { Thermal conductivity of target material }(\mathrm{W} / \mathrm{m}-\mathrm{K}) \\ \text { THCFR } & =\text { Thermal conductivity of fuel }(\mathrm{W} / \mathrm{m}-\mathrm{K}) \\ \text { TMLTOX } & =\text { Fusion temperature of oxide (K) } \\ \text { TMLTCL } & =\text { Fusion temperature of cladding (K) } \\ \text { TMLTTR } & =\text { Fusion temperature of target material (K) } \\ \text { TMLTFR } & =\text { Fusion temperature of fuel (K) } \\ \text { NOXCL } & =\text { Indices for ordering oxide layer species } \\ \text { NCL } & =\text { Indices for ordering cladding species } \\ \text { NTR } & =\text { Indices for ordering target species } \\ \text { NFR } & =\text { Indices for ordering fuel species }\end{array}$

Note that NOXCL, NCL, NTR, and NFR must be ordered in ascending terinperature scale starting from 1.

\begin{tabular}{ll} 
5. NAMELIST RPEAK \\
\hline JMAX & $=$ Number of radial rings \\
RPF & $=$ Radial peaking factors
\end{tabular}

\section{NAMELIST SOURCE}

$\begin{array}{ll}\text { KFP } & =\text { Total number of fission products selected } \\ \text { PWRASS } & =\text { Total assembly power (W) } \\ \text { KSP } & =\text { Total number of source term species selected } \\ \text { NFP } & =\text { Ordering of source term species in the selection rule } \\ \text { CODK } & =\text { Coefficient in the fission product decay power expression (CODK/TIME } \\ \text { ENODK } & =\text { Coefficient in the fission product decay power expression (CODK/TIME } \\ \text { IFPDK } & =\text { FNODK) } \\ \text { FRCZRO } & =\text { Initial decay fraction } \\ \text { MKINL } & =\text { Initial mass fraction of fission product species in each tube }\end{array}$




\section{Table A-1. Variable Definition}

XKZERO = Pre-exponential factor used in Arrhenuis expression for fission product release

EA $\quad=$ Activation energy used in Arrhenuis expression for fission product release (J/kg-mole)

7. NAMELIST XPEAK

IMXASS $=$ Number of axial nodes

XPF $\quad=$ Axial peaking factors 


\section{Table A-2. Input Deck SRPIN.DAT}

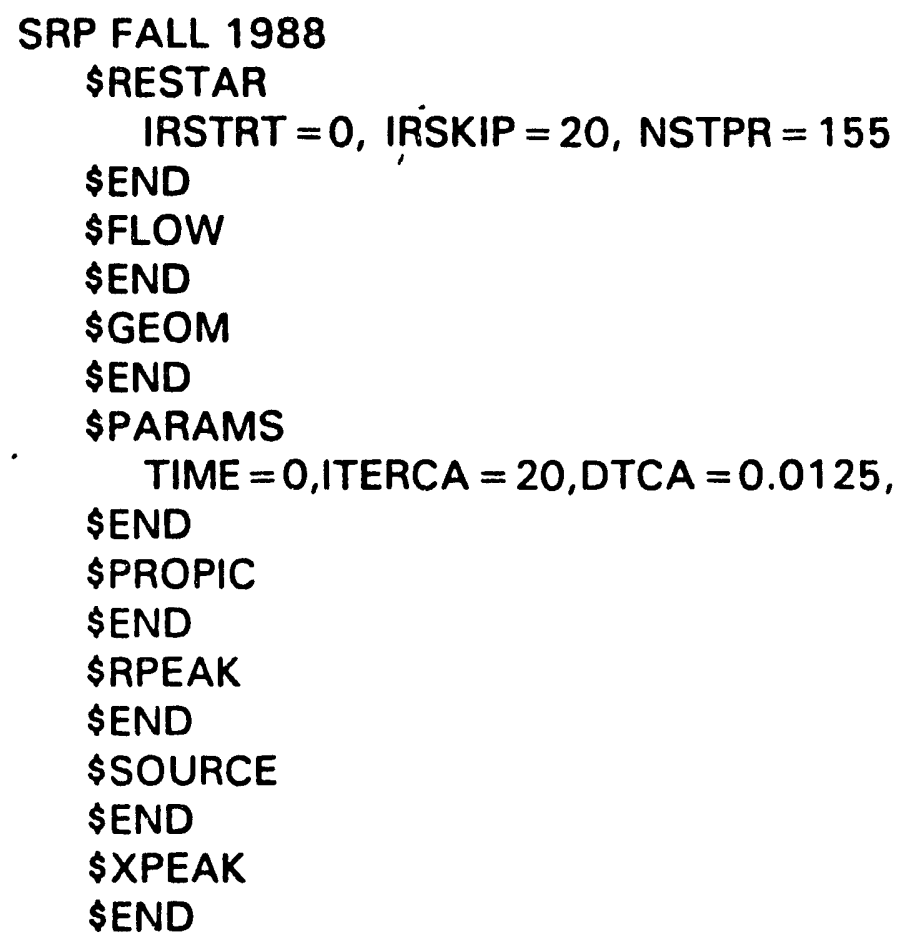




\section{External}

\section{C.N. Amos}

Science Applications International Corp. 2100 Air Park Road S.E.

Albuquerque, New Mexico 87106

S. D. Clement

Science Applications International Corp. 2100 Air Park Road S.E.

Albuquerque, New Mexico 87106

P.R. Davis

PRD Consulting

1935 Sabin Drive

Idaho Falls, Idaho 83401

W. L. Ferrell

924 Clover Circle

Lafayette, Colorado 80026

J.H Holderness

Science Applications International Corp. 1910 Deacon Street

Los Alamos, New Mexico 87545

Kamiar M. Jamali

Dept. of Energy

OEAS-DP62/GTN

Washington, D. C. 20585

Mohsen Khatib-Rahbar

ERI

6290 Montrose Rd.

Rockville, Maryland 20852

Herbert J. C. Kouts

Defense Nuclear Facilities Safety Board 625 Indiana Avenue, N.W.

Suite 700

Washington D.C. 20004

Herbert Massey

Defense Nuclear Facilities Safety Board 625 Indiana Avenue, N.W.

Suite 700

Washington D.C. 20004 
Thomas Matteson:

1933 Little River Road

Flat Rock, North Carolina 27831

J. Meyer

Scientech

11821 Parklawn Dr.

Ste. 100

Rockville, Maryland 20852

David Okrent

UCLA

Boelter Hall, Room 5532

Los Angeles, CA 90024-1597

Norman Rasmussen

M. I. T.

77 Massachusetts Ave.

Cambridge, Massachusetts 02139

Desmond Stack

Los Alamos National Labotatory

Group Q-6 Mail Stop K 557

Los Alamos, New Mexico 87545

D. A. Ward

2108 Pisgah Road

North Augusta, South Carolina 29841 
WSRC-RP-92-759

This page intentionally left blank.

Dist- 3 

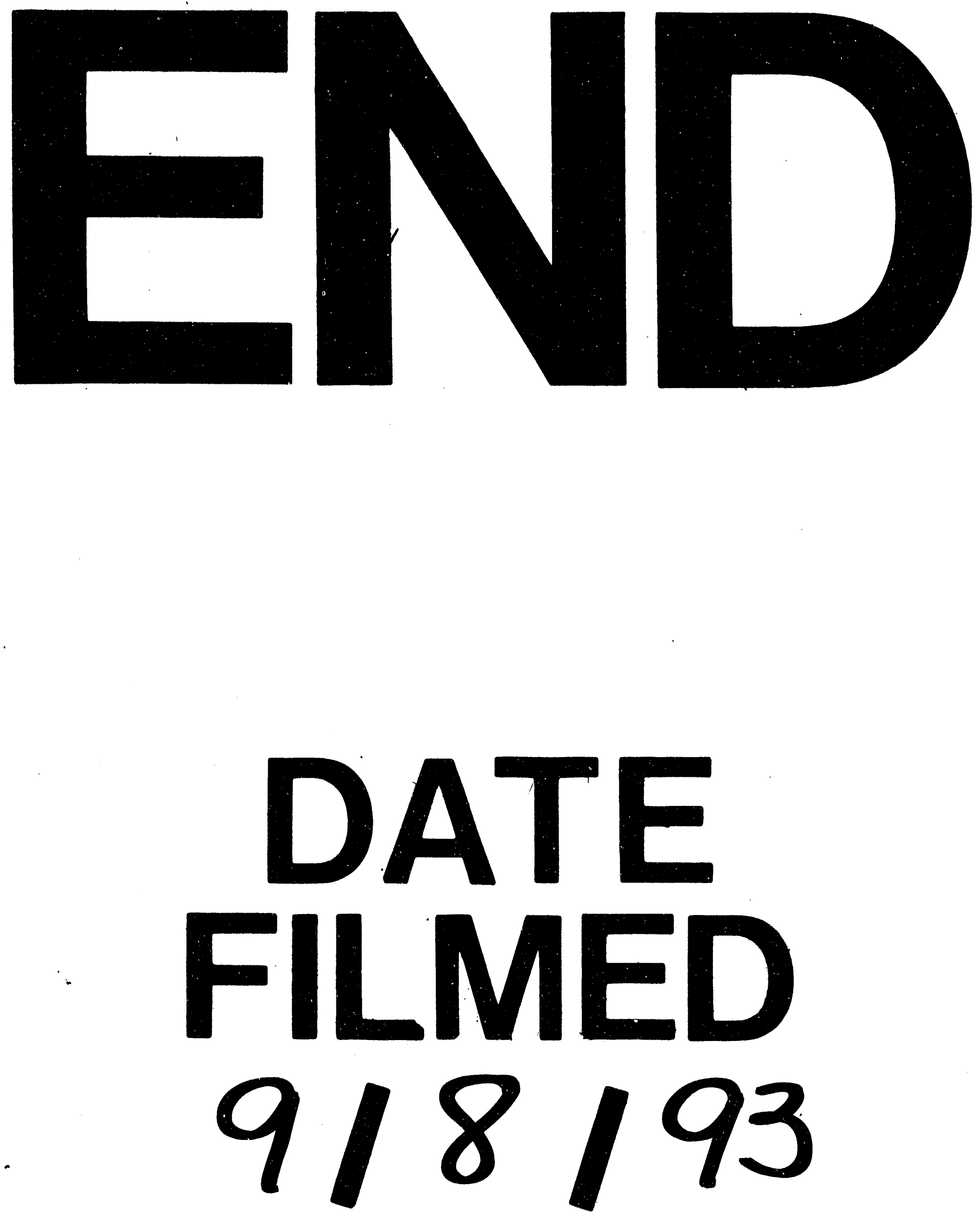


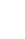

